\title{
Towards progressive regulatory approaches for agricultural applications of animal biotechnology
}

\author{
Eric M. Hallerman (D) - Justin P. Bredlau (D) - Luiz Sergio A. Camargo (D) \\ Maria Lucia Zaidan Dagli (iD • Margaret Karembu • Godfrey Ngure • \\ Rhodora Romero-Aldemita • Pedro Jesús Rocha-Salavarrieta (1) • \\ Mark Tizard (i) - Mark Walton • Diane Wray-Cahen $(\mathbb{D}$
}

Received: 25 August 2021 / Accepted: 7 December 2021 / Published online: 9 January 2022

(C) The Author(s) 2021

\begin{abstract}
Traditional breeding techniques, applied incrementally over thousands of years, have yielded huge benefits in the characteristics of agricultural animals. This is a result of significant, measurable changes to the genomes of those animal species and breeds. Genome editing techniques may now be applied to achieve targeted DNA sequence alterations, with the potential to affect traits of interest to production of agricultural animals in just one generation. New opportunities arise to improve characteristics difficult to achieve or not amenable to traditional breeding, including disease resistance, and traits that can improve animal welfare, reduce environmental
\end{abstract}

E. M. Hallerman ( $\square)$

Virginia Polytechnic Institute and State University,

Blacksburg, VA, USA

e-mail: ehallerm@vt.edu

J. P. Bredlau · D. Wray-Cahen

U.S. Department of Agriculture, Washington,

DC, USA

L. S. A. Camargo

EMBRAPA—Brazilian Agricultural Research

Corporation, Juiz de Fora, MG, Brazil

M. L. Z. Dagli

School of Veterinary Medicine and Animal Science, University of Sao Paulo, São Paulo, SP, Brazil

M. Karembu · G. Ngure

International Service for the Acquisition of Agri-Biotech

Applications AfriCenter, Nairobi, Kenya impact, or mitigate impacts of climate change. Countries and supranational institutions are in the process of defining regulatory approaches for genome edited animals and can benefit from sharing approaches and experiences to institute progressive policies in which regulatory oversight is scaled to the particular level of risk involved. To facilitate information sharing and discussion on animal biotechnology, an international community of researchers, developers, breeders, regulators, and communicators recently held a series of seven virtual workshop sessions on applications of biotechnology for animal agriculture, food and environmental safety assessment, regulatory approaches,

\author{
R. Romero-Aldemita \\ ISAAA SEAsia Center, Los Banos, Philippines \\ P. J. Rocha-Salavarrieta \\ InterAmerican Institute for Cooperation On Agriculture, \\ San José, Costa Rica \\ M. Tizard \\ Commonwealth Scientific and Industrial Research \\ Organisation, Geelong, VIC, Australia \\ M. Walton \\ AquaBounty, Maynard, MA, USA
}


and market and consumer acceptance. In this report, we summarize the topics presented in the workshop sessions, as well as discussions coming out of the breakout sessions. This is framed within the context of past and recent scientific and regulatory developments. This is a pivotal moment for determination of regulatory approaches and establishment of trust across the innovation through-chain, from researchers, developers, regulators, breeders, farmers through to consumers.

Keywords Genome editing - Genetic modification · Genetic engineering · Public policy · Regulatory cooperation - International trade - Public acceptance . Livestock

\section{Introduction}

A number of global trends contribute to the need for heightened investment in the development and distribution of genetically improved agricultural animals. This need is heightened by increased demand for animal-based protein due to growing prosperity and decreasing arable land for agriculture. Further, ongoing climate change is increasing physiological stress upon production animals, contributing to outbreaks of new diseases and expanding ranges of pests and disease vectors. There is also a growing interest in animal welfare among farmers and consumers. Against this background, the animal production sector needs to genetically improve breeding and production stocks to increase efficiency and decrease losses, with the goal of producing more food with fewer resources. While broader application of classical selective breeding can make valuable contributions to genetic improvement, researchers and developers are applying rDNA techniques and genome editing (GnEd; see Glossary of Terms) to achieve outcomes that would not otherwise be possible, as well as combining $\mathrm{GnEd}$ techniques with genomic selection (Meuwissen 2007) to achieve genetic advances much more quickly than could be achieved by conventional breeding methods.

\section{Genetic modification using rDNA techniques}

Historically, the term 'genetically modified' (GM) has referred to organisms, including animals, that are produced by classical gene transfer methodologies in which an introduced recombinant DNA (rDNA) construct integrates randomly into the host genome, or by breeding of transgenic founders that transmit that rDNA construct to their descendants. It has been over forty years since the first report of using rDNA technology to modify animal DNA, mouse embryos expressing an SV40-thymidine kinase construct (Gordon et al. 1980). Following soon after, growth hormone transgenic mice growing to large size were produced, demonstrating that traits relevant to agriculture might be purposefully approached (Palmiter et al. 1982, 1983). This led to considerable subsequent research with larger, agricultural animals (Hammer et al. 1985, Fig. 1). Examples of such applications include cattle modified for improvement of milk composition (Liu et al. 2017) and mastitis resistance (Donovan et al. 2005); pigs for growth rate (Purcell et al. 1990), milk composition (Tong et al. 2011), and phytate utilization (Forsberg et al. 2003); sheep for growth rate (Adams et al. 2002) and wool growth (Damak et al. 1996), chickens for disease resistance (Lyall et al. 2011), and fishes for growth rate (Du et al. 1992) and disease resistance (Dunham et al. 2002). Despite the development of many promising GM animals, only one GM animal food product has reached the marketplace, the AquaBounty "AquAdvantage" salmon. The salmon are now being produced in the United States after a U.S. production facility was approved by U.S. Food and Drug Administration (2018) and a ban on import of fertilized eggs was lifted in 2019. In May 2021, Brazilian regulators approved the AquAdvantage salmon for sale and consumption in that country. Field trials have been completed in Argentina, and Chinese authorities have authorized AquaBounty to conduct regulatory trials.

Many promising GM animals have not achieved regulatory approval. For example, the EnviroPig was a transgenic pig synthesizing phytase in the salivary glands and secreting active enzyme in the saliva, enabling them to utilize practically all the phosphorus in cereal grains and soybean meal and to excrete fecal material containing $60 \%$ less phosphorus than nontransgenic pigs (Golovan et al. 2001; Forsberg et al. 2003). It received environmental approval in Canada for commercial production (Government of Canada 2012), but the application for food approval in Canada and the United States was discontinued in 2012. The developer cited the expense, length, and uncertainty of 


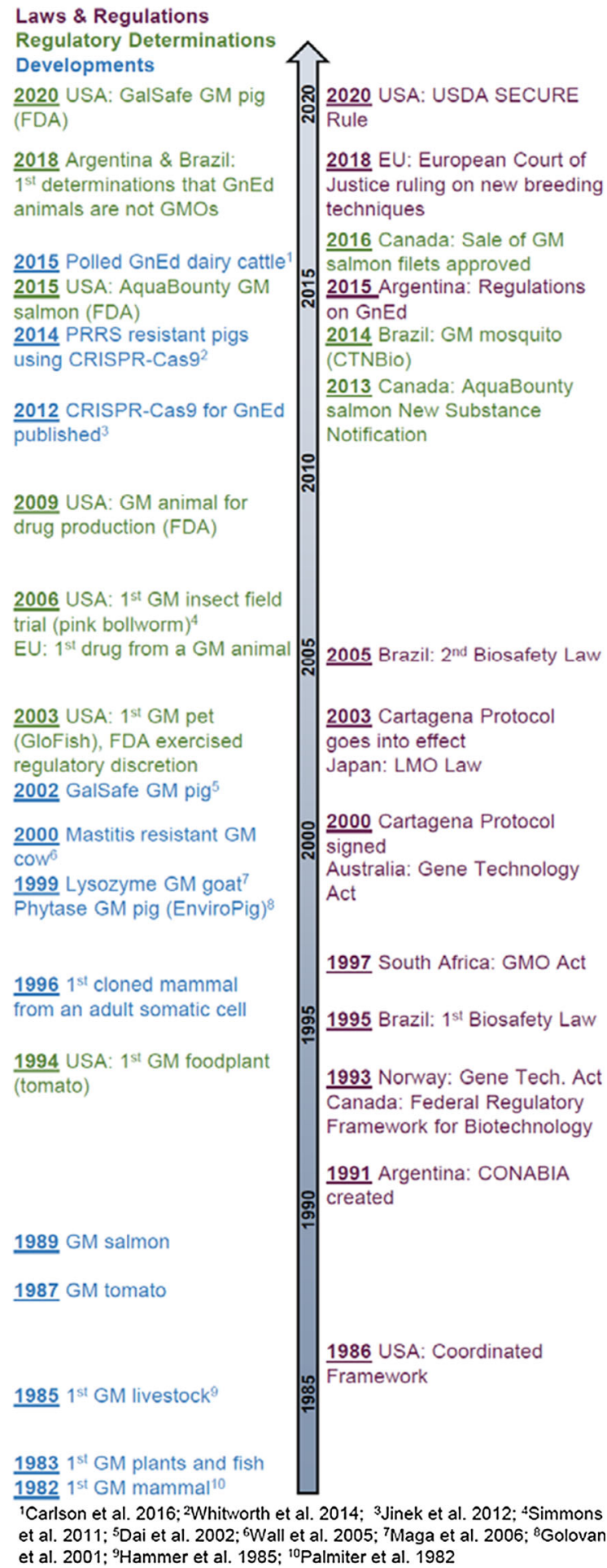

Fig. 1 Timeline of major scientific and regulatory developments of animal biotechnology for agriculture. Note years for developments are by date of modification, if reported, or otherwise by publication year (see footnote references) the approval process as key factors for ending the program.

The U.S. Food and Drug Administration (2020) recently approved an rDNA construct inserted into a line of domesticated pigs using homologous recombination, referred to as GalSafe pigs. These GM pigs were developed for biomedical uses and are approved for use both as food and for use in human therapeutics. Other GM animals still in the R\&D pipeline include pigs expressing bovine $\alpha$-lactoglobulin in milk to improve pig growth and health (Bleck et al. 1998) and goats expressing lysozyme in milk, which may have human health benefits as well as increased shelf life (Maga et al. 2006; Cooper et al. 2013). While classical gene transfer methods were effective for the development of these animals, more so with the advent of somatic cell nuclear transfer or cloning, integration rates were relatively low. Typically, only one to several percent of microinjected embryos subsequently expressed the inserted gene, and integration of the construct was at random sites across the genome, raising concern for insertional mutagenesis and animal welfare.

Advent of genome editing

Techniques have recently been applied to agricultural animals to alter a DNA sequence at a targeted site in the host genome using a genome editor to delete, insert, or change nucleotides in a DNA sequence. Genome editors are a set of molecular tools that allow researchers to modify the genome with a higher rate of success and higher precision than previous rDNA technologies. While different genome editors are available, such as zinc finger nuclease (ZFN) and transcription activator-like effector nucleases (TALENs), the newer "clustered regularly interspaced short palindromic repeats" associated nuclease system (CRISPR/Cas9) has become the choice of most developers. CRISPR/Cas9 utilizes small RNAs that recognize a specific DNA sequence to guide the nuclease to the correct target in the genome and to generate a DNA cleavage. The break in the DNA molecule will be repaired by non-homologous endjoining or homology-directed repair, which results in mutation via deletion, insertion, or changing of one or more nucleotides at a targeted site. With homologydirected editing, a DNA template directs the editing of the sequence for a target mutation (Doudna and 
Charpentier 2014). The CRISPR-Cas9 system is easy to design and assemble, can target any gene in the genome, can work with different nucleases to induce single- or double-strand breaks and can edit single or multiple sites simultaneously when using multiple guides (Chandrasegaran and Carrol 2016; Wu et al. 2018). Homologous recombination, such as the technique used to produce GalSafe pigs, occurs at a rated estimated at one in a million cells. The rate of success for editing the genome of, for example, cattle embryos can range from $13 \%$ to higher than $90 \%$ (Owen et al. 2020; Camargo et al. 2020), varying with the approach employed, the targeted gene and the type of genetic modification intended (e.g., deletion, substitution, or insertion). Reported rates of success across livestock species have ranges from 12.5 to $100 \%$ (Tan et al. 2013; Navarro-Serna et al. 2020). Moreover, CRISPR/ Cas9 can be used to modulate gene expression when combined with transcription regulators (Pickar-Oliver and Gersbach 2019). All of these features make the CRISPR/Cas9 system more flexible, creating more possible applications than other GnEd tools.

Promising applications of genome-edited agricultural animals are in the research and development pipeline. While GnEd techniques have been used to create transgenic or GM animals, most developers and breeders have focused on creating cisgenic animals that could have been created via conventional breeding methods, albeit much more slowly and with less control over the breeding process. The research and developer communities seek to bring these $\mathrm{GnEd}$ animals forward to agricultural production and the consumer marketplace. These communities would benefit by learning from experiences with GM plants and animals and engage the regulatory community, producers, and public proactively to ease access to the marketplace, utilizing effective communication strategies to inform useful dialogue as opposed to endless debate.

Workshops on regulatory approaches for agricultural applications of animal biotechnology

In 2011, Argentina held the First International Workshop on the Food and Environmental Safety Assessment of GM Animals in Buenos Aires. Since that time, two additional in-person international workshops have been held in Brasilia, Brazil and Charlottesville, VA,
USA to discuss the range of issues associated with animal biotechnologies and their regulation (https:// sites.google.com/a/vt.edu/animalbiotechresources/ third-annual-2017). With the ongoing COVID-19 pandemic, a planned in-person meeting was not possible in 2020. Instead, those involved with organizing previous in-person workshops offered virtual workshops for the animal biotechnology research, breeding, and regulatory communities over seven sessions from September to December 2020 (https://sites.google. com/a/vt.edu/animalbiotechresources/2020-onlineworkshops). Five sessions combined presentations and discussion panels that covered topics including food safety assessment, environmental risk assessment, GnEd regulatory approaches, recent developments in animal biotechnologies and animals in the research pipeline, effective communication, and fostering of market and public acceptance. Two sessions consisted of smaller regional breakout groups with active dialog covering topics such as communication, regulatory approval, marketing and trade, and region-specific issues. The number of participants per webinar session varied from 101 to 277, with somewhat fewer participants attending the breakout groups; a total of 497 individuals from 51 countries took part across the seven sessions. The session on regulatory approaches for GnEd animals attracted the most participants, demonstrating the global interest in this topic. In this review, we summarize the topics presented and discussed, with additional context to inform the wider community of biotechnology researchers, developers, breeders, and regulators.

\section{Delivering the promise of genome editing}

Status of genome editing in food animals

The rise of genome editors opened new opportunities for genetic improvement of livestock, especially when combined with information gathered through sequencing of livestock genomes. In a given animal breed, GnEd technologies can: (1) promote the introgression of a gene or allele associated with a favourable trait found in other breeds, without requiring crossbreeding and unintended introgression of linked traits (TaitBurkard et al. 2018); (2) modify quantitative traits associated with several quantitative trait nucleotides to increase the frequency of favourable alleles (Jenko 
et al. 2015); and (3) delete genes with deleterious or undesirable effects (Whitworth and Prather, 2017). Thus, genome editors can be applied to improve meat and milk composition, improve animal welfare and climate resilience, increase disease resistance, and enhance agricultural productivity.

Genome editors can be used to improve the welfare of livestock. For cattle, horns present risks to farmers and other animals, and farmers frequently remove horn buds from young calves using chemicals or a hot iron. The introgression of a polled allele from a naturally hornless polled breed into the genome of embryos from a horned breed resulted in hornless, or polled, calves (Carlson et al. 2016), with no need for subsequent disbudding. For pigs, several genes are being targeted to reduce or eliminate boar taint in pork (Telugu 2020), which could eliminate the need to castrate male pigs.

Genome-edited traits could help cattle to be more acclimated to warmer temperatures, improving animal welfare and livestock productivity in the tropics. A black coat absorbs more solar radiation and retains more heat than a white coat, contributes to increased body temperature (Hilmann et al. 2001), and can impair production and reproductive functions (King et al. 1988). Dilution of black color in Holstein cattle was achieved by the introgression of mutations in the pre-melossomal protein 17 gene, resulting in a calf with a grey and white coat (Laible et al. 2020). Some cattle breeds present a slick, short-hair phenotype due to mutations in the prolactin receptor (PRLR) gene, which improves the animal's ability to manage body temperature (Porto-Neto et al. 2018). Introgression of such PRLR alleles can generate animals with slick, short hair (SLICK) and increase heat tolerance in thermally sensitive breeds (Hansen 2020), such as Angus and Holstein.

Resistance to livestock diseases also can also be enhanced by GnEd. Porcine reproductive and respiratory syndrome (PRRS) is a viral disease that affects the respiratory and reproductive systems of swine and results in large economic losses for the pork production industry worldwide (Neumann et al. 2005). Deletion of the CD163 gene, which encodes a cellsurface protein that mediates the entry of the PRRS virus into the host cells, or the deletion of its scavenger receptor cysteine-rich domain 5 , conferred resistance to the infection (Whitworth and prather 2017; Burkard et al. 2018; Xu et al. 2020). The PRP gene has been knocked out to provide resistance to all sources of prion disease, including "mad cow" disease (Richt et al. 2007). Park et al. (2020) used CRISPR/Cas9 to introduce novel PRNP (prion gene) allelic variants into cattle embryos that have been shown to provide resilience to human prions. Genome editing can be applied to enhance resilience to important diseases of poultry, such as avian leukosis (Lee et al. 2017).

Genome editing may be utilized for genetic alterations affecting production, product quality or creating foods with different nutrient profiles. Cows lacking expression of the beta-lactoglobulin protein, one of the main allergens in cow milk, were generated by deleting or silencing the gene that encodes the protein (Wei et al. 2018). Sheep with deletion of the myostatin gene exhibit heavier weight than wild-type individuals (Crispo et al. 2015).

With high fecundity and external fertilization and development, fishes offer an attractive system for GnEd. CRISPR/Cas9 editing is being applied to at least 11 aquaculture species to achieve reproductive confinement, increase growth rate, improve disease and pest resistance, increase omega-3 fatty acid content, or affect pigmentation (Zhu and Ge 2018; Gratacap et al. 2019). For example, GnEd has been applied to knock out the myostatin gene of common carp (Zhong et al. 2016), red sea bream (Kishimoto et al. 2018), olive flounder (Kim et al. 2019), and yellow catfish (Zhang et al. 2020) to achieve greater muscling and filet size. To achieve reproductive confinement of cultured Atlantic salmon, Wargelius et al. (2016) deleted the $d n d$ gene to induce germ-cell ablation, with concurrent deletion of slc45a2, yielding albinos as a phenotypic marker.

There are other opportunities to apply GnEd to improve quantitative traits that are controlled by single genes, and many other opportunities may emerge with the identification of new targets and their effects. Progress in the science and practice of GnEd may allow introduction of multiple edits with positive effects on quantitative traits controlled by many genes, which in turn may result in a greater response to selection when combined with genomic selection in livestock breeding programs (Jenko et al. 2015; Georges et al. 2019). 
Moving towards practical application

Work on GnEd animals has moved beyond proof of principle toward practical applications that would optimize livestock for microenvironments and purposes faced by millions of small farmers. Commercialization of GnEd animals could improve animal well-being, provide economic benefits to farmers, and promote sustainability. Ideally these breeding technologies will be developed with the engagement of stakeholders, including farmers and consumers (Brody 2020). Bringing forward the achievements of research and development (R\&D) to commercial application will require partnerships among universities, government research institutes and the private breeding and production sectors. For example, application of $\mathrm{GnEd}$ to introduce indels into the bovine $\beta$-lactoglobulin gene is going forward through collaboration between INTA (Instituto Nacional de Tecnología Agropecuaria) and the Universidad de San Martin in Argentina. Acceligen is actively working on 12 traits in cattle, swine, and fish (Sonstegard 2020). Noting that twothirds of global cattle population is held by 300 million small holders, Acceligen and collaborators aim to generate dairy animals that will bring about significant and sustainable production gains through immediate access to improved heat-tolerant and disease-resistant dairy cattle, particularly for African dairy production systems. Acceligen (USA), Kheiron Biotech (Argentina), and TransOva Genetics (USA), with support from the Bill and Melinda Gates Foundation, are collaborating to combine valued traits from the Brazilian Gir (a breed tolerant of tropical conditions with origins in India) and Holstein (a breed with high milk production) cattle. Targeted genes and traits will include polled, SLICK, and trypanosome parasite resistance, with the aim of dramatically increasing production in South American (Sammartino 2020) and African herds. The Mzima cow project of the Centre for Tropical Livestock Genetics and Health, with support from UKAid and the Bill and Melinda Gates Foundation, is aimed at producing GnEd cattle expressing a synthetic trypanolytic factor derived from the baboon ApoLI gene to make them resistant to trypanosomes, the parasite responsible for African sleeping sickness (Kemp 2020). Genome editing of polo horses has been undertaken by the Proinvesa Group of Argentina (Knapton 2017; Sammartino 2020). The swine production industry is interested in applying GnEd to address the multi-billion dollar impacts of the PRRS virus (Whitworth et al. 2014, Burkhard et al. 2018, Xu et al. 2020, Brody 2020) and to improve animal welfare by eliminating the need for castration to prevent boar taint in pork (Telugu 2020). In poultry, marker-assisted sex selection has been proposed as a replacement for culling of day-old male chicks in the egg layer industry. Inserting the marker gene into the male-determining sex chromosome would enable male eggs to be identified and removed at point of lay. The female eggs, not carrying the marker gene, would be incubated and hatched as hens to lay eggs for food production and hopefully would not be regulated as GM in Australia, as the hens would be "null segregants" (Doran et al. 2016a), though such determinations might vary among jurisdictions. Other practical applications in poultry include introduction of disease resistance to improve animal welfare and reduce potential for zoonotic spread of diseases (in particular, avian influenza), and improvement of food safety by deletion of allergen-encoding sequences (Doran et al. 2016a, b; Oishi et al. 2016).

\section{Food safety aspects of genetically modified and genome edited animals}

Technical methods applied in animal biotechnology have evolved, and GnEd techniques are becoming widely applied to develop animals with new traits. Whatever the biotechnological approach, there is a widely perceived need to assure the public of the food safety of products from genetically modified animals. National and supranational bodies have worked to develop policies for that purpose (see Fig. 1 for timeline); many have done so for organisms developed using classical rDNA technology methods. Additionally, most countries are signatories of the Convention of Biological Diversity (CBD) and the Cartagena Protocol on Biosafety (CPB), a regulatory framework generated to govern transboundary movement of living modified organisms (LMOs) and to ensure human health and environmental safety. The development of GnEd techniques is relatively recent, and therefore, many countries and supranational bodies have yet to determine their regulatory posture. As noted below, the majority of countries with regulatory policies for GnEd organisms distinguish between GM and GnEd products based on the definition of LMO 
established in the Cartagena Protocol on Biosafety (Secretariat of the Convention on Biological Diversity 2000). In this section, we review issues pertinent to food safety assessment and associated policies for oversight of GM and GnEd animals as reported in the virtual workshops.

Food safety assessment of foods derived from recombinant DNA-bearing animals

The safety of foods derived from GM and GnEd animals is important to consumers and likely will prove a critical issue for adoption of such foods. How should regulatory authorities approach food safety assessment? The CODEX Guidelines for the Conduct of Food Safety Assessment of Food Derived from Recombinant-DNA Animals (FAO 2008) is a highly influential document informing the development of national food safety assessment policies. The scope of the Guidelines is restricted to food safety and nutritional issues and to foods from animals with a safe history of use as sources of food. They are designed for food derived from recombinant-DNA (rDNA) bearing animals, although the approach could be applied to foods from animals altered by other techniques, including GnEd. The Guidelines embody a flexible, case-by-case assessment; comparisons of food safety are made to foods from conventionally bred counterparts, with a focus on intended and any unintended changes.

A number of changes were made to adapt the existing Codex guidelines for foods derived from rDNA plants to those from rDNA animals. Among terminology and definitions changed, the "host" is now the "recipient animal prior to the genetic modification". Distinction is now made between the "initial rDNA animal" (i.e., the founder animal) and the "final rDNA animal used for food"; that is, some founder animals prove to be mosaics, and additional breeding is required to ensure that the insertion is germ-line transmissible, and the focus of the food safety assessment is on the final rDNA animal. The definition of "conventional counterpart" has been revised to better reflect animal breeding practices. The assessment of potential allergenicity (including the Annex) remains the same as in the Plant Guidelines. The assessment of potential toxicity has been expanded to include bioactivity, recognizing that some modifications to animals may involve the expression of bioactive substances (e.g., hormones such as growth hormone); the food safety assessment should therefore include consideration of whether such substances may be active in humans, taking into account impacts of processing and cooking. The assessment also may be informed by the health status of the rDNA animal. The general approach to the assessment of potential toxicity remains the same as the Plant Guideline. Aspects relating to compositional analysis have been changed to include reference to the choice of comparator-ideally matched in husbandry/housing conditions, age, sex, parity, lactation, laying cycle, and other relevant factors. Application of the Codex rDNA Animal Guideline to the products of genome editing is yet before us. While only limited examples of rDNA animals for food use exist, applying the Codex Animal Guideline is essentially no different than applying the well-accepted Plant Guideline.

Regulatory approaches for food safety of genome edited animals

Unlike GM methods that rely on random insertions of rDNA (often from other species), GnEd enables precise changes equivalent to those that could be obtained by conventional breeding techniques. The fact that GnEd uses biotechnology but allows generation of conventional products has raised challenges from the regulatory point of view. Hence, government policies have been generated, reviewed, or adapted to guarantee biological safety while enabling innovation (ECLAC et al. 2019).

Underlying any regulatory policy are the definitions of regulated articles, which thereby define the scope of regulation. Technical definitions underlying existing biotechnology regulatory policies may need to be updated to encompass new breeding technologies, such as GnEd. For example, Food Standards Australia New Zealand (FSANZ), a binational government agency, adopted standards for assessing safety of foods produced using classical gene transfer methods in 1999. Noting that it was unclear whether foods derived using newer GnEd methods are captured using these definitions, FSANZ (2019) recently completed a review of the safety of foods derived from new breeding technologies (NBTs). Among the key findings, definitions in the existing code for 'food produced using gene technology' and 'gene 
technology' are no longer appropriate, as they lack clarity, are outdated, and do not reflect the diversity of techniques now in use. FSANZ found that there may be a case, based on low risk, for some foods derived from new GnEd techniques to be excluded from the requirement for pre-market safety assessment. However, there are divergent views among stakeholders about the acceptability and risk of foods derived from new biotechnologies and how best to regulate them. These findings led to recommendations for updating definitions to better accommodate new and emerging technologies, increasing clarity regarding what foods are captured for pre-market approval, and regulating foods derived from new technologies in a manner commensurate with the risks posed. Public consultations were expected to begin in 2021.

Different approaches to definition of new animal breeding technologies and oversight of food safety of associated products have been adopted among countries and groups of countries. Most countries (the exceptions being the United States and Canada) have GMO laws, and the definition of GMO or LMO determine whether a particular product, technology or type of modification is under the jurisdiction of that country's GMO regulations. The respective countries and international unions differ in terms of legal authorities (often Codex Alimentarius-FAO and WHO 2021) and lead agencies (often a food safety agency or an agency within the ministry of agriculture). Comparisons and contrasts are summarized in Table 1. Among countries that have taken any action, Argentina was first and in 2015 approved Resolution $173 / 15$, which established a procedure to determine whether a product obtained using NBTs would be subject (or not) to the existing GM regulation. If a GnEd animal did not contain foreign DNA (i.e., was not transgenic), then it would not be considered a GMO and would be regulated as a conventionally bred animal. In 2020, the Biosafety Commission worked on updating the regulations for products obtained through NBT. Finally, the updated resolution (Resolution 21/2021, see: https://www.boletinoficial.gob.ar/ detalleAviso/primera/240529/20210208?busqueda= 1) was made official in 2021, covering plants, animals, and microorganisms. In Brazil, an expert group was convened in 2015 to elaborate rules for consultation involving NBTs, and in 2018 Normative Resolution No. 16 (RN16) was approved and adopted by CTNBio, which referred to Precision Breeding Innovative
Techniques (TIMP). The RN16 considers that TIMP encompass a set of new methodologies and approaches that differ from the transgenic genetic engineering strategy, as it results in the absence of recombinant DNA/RNA in the final product. Examples of TIMP are presented in Annex 1 of RN16 and included (but are not limited to) RNA-dependent DNA methylation, site-directed mutagenesis, oligonucleotide-directed mutagenesis, RNAi for topical/systemic use, and viral vectors, with the inoculation of living organisms with recombinant viruses (DNA or RNA) expressing the genetic modification and amplification of the gene of interest through viral replication mechanisms, without modifying the host genome. The first consultations were held in the second semester of 2018 regarding genetically engineered yeasts and the genome-edited polled cattle (Nascimento 2020). A rapidly growing Nile tilapia was determined to be conventional. The application for GnEd polled cattle was withdrawn, however, after vector DNA was found in its genome. Genome-edited cattle with the polled and SLICK traits that do not contain the foreign vector DNA have since been determined to be conventional in Argentina.

The Japanese government in 2019 defined GnEd products derived by modifications of the SDN-1 type (i.e., directed mutation without using a DNA sequence template) as not representing LMOs according to the Japanese Cartagena Act (Tsuda et al. 2019; Tsuda and Ohsawa 2020). In such cases, the government requests that developers provide information on the development processes for the purpose of accumulating knowledge related to GnEd of organisms and agree to publish part of that information on the Japan Biosafety Clearing House website. Within the European Union, a GM organism is defined as having genetic material that has been altered in a way that does not occur naturally by mating or natural recombination. Taking an approach different from that of most other countries, the Norwegian Biotechnology Advisory Board has proposed a three-tiered system, with the tier depending on the risk category and type of genetic alteration (Brattlie et al. 2019). Organisms with "foreign" DNA or transgenic alterations would require standard GMO assessment. Those that could arise via conventional breeding would require only notification (with confirmation). A third category of expedited assessment would exist for organisms with other species-specific genetic changes. The proposal is currently under discussion (Holst Jensen 2020). The 
Table 1 Approaches to oversight of food safety of products of animal biotechnology in selected countries and supranational groups

\begin{tabular}{|c|c|c|c|c|c|c|}
\hline $\begin{array}{l}\text { Country/ } \\
\text { Union }\end{array}$ & Regulatory agency & $\begin{array}{l}\text { Regulatory policy for } \\
\text { GM animals? }\end{array}$ & $\begin{array}{l}\text { Consistent } \\
\text { with Codex } \\
\text { Alimentarius? }\end{array}$ & $\begin{array}{l}\text { GM animal } \\
\text { product } \\
\text { approved for } \\
\text { food? }\end{array}$ & $\begin{array}{l}\text { Regulatory } \\
\text { policy for } \\
\text { GnEd } \\
\text { animals? }\end{array}$ & $\begin{array}{l}\text { Supporting } \\
\text { presentation } \\
\text { or reference }\end{array}$ \\
\hline Argentina & SENASA $^{\mathrm{a}}$ & Yes & Yes & No & Yes $^{\mathrm{b}}$ & $\begin{array}{l}\text { Maggi }(2020) \\
\text { and Whelan } \\
(2020)\end{array}$ \\
\hline $\begin{array}{l}\text { Australia/ } \\
\text { New } \\
\text { Zealand }\end{array}$ & $\begin{array}{l}\text { Food Standards Australia } \\
\text { New Zealand }\end{array}$ & $\begin{array}{l}\text { Yes, Food Standards } \\
\text { Australia New } \\
\text { Zealand Act } 1991\end{array}$ & Yes & No & $\begin{array}{l}\text { No; Code } \\
\text { under } \\
\text { review }\end{array}$ & Kelly (2020) \\
\hline Brazil & $\mathrm{CTNBio}^{\mathrm{c}}$ & $\begin{array}{l}\text { Yes, Biosafety Law } \\
11,105,2005 \text {; also } \\
\text { see } 28 \text { Normative } \\
\text { Resolutions }\end{array}$ & Yes & Yes & Yes & $\begin{array}{l}\text { Finardi } \\
\quad(2020)\end{array}$ \\
\hline Canada & $\begin{array}{l}\text { Canadian Food Inspection } \\
\text { Agency, Health Canada, } \\
\text { othersd }\end{array}$ & Yes & Yes & Yes & $\mathrm{NA}^{\mathrm{e}}$ & $\begin{array}{l}\text { Cianciarelli } \\
\text { (2020) }\end{array}$ \\
\hline Japan & $\begin{array}{l}\text { Ministry of Health, Labor, } \\
\text { and Welfare }\end{array}$ & Yes & Yes & No & Yes & $\begin{array}{l}\text { Tsuda and } \\
\text { Ohsawa } \\
(2020)\end{array}$ \\
\hline Philippines & $\begin{array}{l}\text { Department of Agriculture, } \\
\text { Bureau of Animal Industry }\end{array}$ & No & Yes & No & No & $\begin{array}{r}\text { Mingala } \\
(2020)\end{array}$ \\
\hline $\begin{array}{l}\text { South } \\
\text { Africa }\end{array}$ & $\begin{array}{l}\text { Department of Science and } \\
\text { Innovation }\end{array}$ & Yes & Yes & No & No & $\begin{array}{l}\text { Groenewald } \\
(2020)\end{array}$ \\
\hline $\begin{array}{l}\text { United } \\
\text { States }\end{array}$ & $\begin{array}{l}\text { Department of Health and } \\
\text { Human Services, Food and } \\
\text { Drug Administration; } \\
\text { others } \mathrm{f,g}\end{array}$ & Yes & Yes & Yes & Yes & $\begin{array}{l}\text { Kanelakis } \\
(2020)\end{array}$ \\
\hline $\begin{array}{l}\text { African } \\
\text { Union }^{\mathrm{h}}\end{array}$ & - & NA & NA & NA & NA & $\begin{array}{l}\text { Nengomasha } \\
\quad(2020)\end{array}$ \\
\hline $\begin{array}{l}\text { European } \\
\text { Union }\end{array}$ & $\begin{array}{l}\text { European Food Safety } \\
\text { Authority }\end{array}$ & Yes & Yes & No & No & EFSA (2012) \\
\hline
\end{tabular}

${ }^{a}$ Servicio Nacional de Sanidad y Calidad Agroalimentaria

${ }^{\mathrm{b}}$ Updated policy under consideration

${ }^{\mathrm{c}}$ National Biosafety Technical Commission

${ }^{\mathrm{d}}$ Others as appropriate to application, may include Environment and Climate Change Canada, Department of Fisheries and Oceans, Agriculture and Agri-Food Canada, Global Affairs Canada, and Innovation, Science and Economic Development Canada

'Canada's regulations are product-based. The method of genetic modification does not determine whether a safety assessment is required; 'novelty' of product is regulatory trigger for pre-market assessment. Canada has a Proposed new guidance for Novel Food Regulations focused on plant breeding

${ }^{\mathrm{f}}$ U.S. Department of Agriculture (USDA), Animal and Plant Health Inspection and Food Safety and Inspection Service released an Advanced Notice of Proposed Rulemaking in December 2020 that may result in a shift of regulatory jurisdiction for some products ${ }^{\mathrm{g}}$ USDA, Food Safety and Inspection Service is responsible for the final safety determination and labeling for certain products, such as meat

${ }^{\mathrm{h}}$ A union of 55 African member states aimed at promoting economic and political integration. Strategy and advisory role, rather than regulatory

interpretation in several EU countries before July 2018 was that organisms with CRISPR/Cas9-induced point mutations are not GMOs; however, the European
Court of Justice in July 2018 ruled that GnEd organisms are GMOs since the genomic DNA has been altered. Notably, chemical- and radiation- 
induced mutagenesis of crop plants was recognized under this definition but excluded on the grounds of a "history of safe use" of such technology, an exclusion not afforded the more precise technology of GnEd. South Africa is considering a governance framework for GnEd proposed by the Academy of Science of South Africa (2017) that advocates a product-based trigger where products of NBTs are classified either as GMOs that will be regulated under GMO Act 15 of 1997 or as non-GMOs that will not be subject to regulation under the Act and would be regulated as conventional products (Groenewald 2020). Clearly, not all countries have express policies for GM animal products, and only a few have taken up issues posed by GnEd animal products. Indeed, because most countries have not received applications for food products derived from GM or GnEd animals and have not readied the relevant policy frameworks, regulatory issues may delay regulatory decisions when such applications ultimately are submitted.

While many countries or supranational authorities have existing systems for ensuring the safety of foods derived from animals (Abley 2020), regardless of the genetic background, the food animal production industry emphasizes that it routinely conducts additional testing and monitoring to assess both food safety and process control (Alvarado 2020). Considerations unique to GM or GnEd products might include assessment of allergenicity of any unique gene products and compositional analysis.

Regulatory process and commercialization of genome-edited animals

Regulatory policy, particularly the definition of what is a regulated article, have important bearing on the progress of a product through the regulatory pathway and hence on the prospect that GnEd animals will come to production in agriculture. We illustrate this influence with case studies of regulatory experiences in selected countries.

In Argentina, seven introduced traits in GnEd animals, including four traits for cattle, one equine, one swine, and one fish, have been presented to regulatory authorities. While the cattle are at the $R \& D$ stage, a GnEd fish developed by AquaBounty is potentially ready for production. The Nile tilapia FLT01 line exhibits increased fillet yield by deletion of the endogenous myostatin gene through a 26-bp deletion creating an early stop codon. Loss of function of that negative regulator of muscle growth leads to increased muscle mass, greater weight, and greater fillet yield than its unedited counterpart. The GnEd fish was created using microinjection with nuclease mRNA; no introduction of DNA was involved. The final product is homozygous for the 26-bp deletion. There are no off-target sites of modification. Critical in regulatory consideration of the FLT-01 fish was lack of new genetic material or unwanted integration of plasmid DNA in the final product. In particular, it does not contain a new combination of genetic material in the genome generated by the application of modern biotechnology, and hence is not covered by the definition of a regulated article under Res. 763 under the Cartagena Protocol. Hence, under Argentine Resolution 173/15-New Breeding Techniques, this fish is not a GMO. Brazil made a similar determination for this GnEd fish in August 2019.

A major global animal GnEd milestone was reach in 2021 when the first food from GnEd animals was marketed in Japan. In 2021, the Ministry of Health, Labor and Welfare (MHLW) determined that two GnEd fishes with increased edible muscle ( GnEd myostatin knockouts in red sea bream Pagrus major and tiger puffer Takifugu rubripe) are not GM and therefore are not subject to a requisite GM food safety review (MHLW 2021). A Kyoto-based start-up, Regional Fish Institute, Ltd., submitted the notifications to MHLW and the Ministry of Agriculture, Forestry and Fisheries to market these fish, which were the result of a collaboration between Kyoto and Kinki Universities (Asahi Shimbun 2021b, a, Yomiuri Shimbun 2021b, a).

The experience of a GnEd polled cattle trait in the Brazilian regulatory process provides a cautionary tale regarding product development and the regulatory process. Under Brazilian Biosafety Law 11.105, a GMO is an organism whose genetic material has been modified by any genetic engineering technique. Genetic engineering is defined by Brazil as the activity of manipulating DNA or RNA recombinant molecules, and recombinant DNA or RNA molecules are molecules manipulated outside live cells through changes made to natural or synthetic DNA or RNA segments that can multiply in a live cell. A petition was submitted to CTNBio for commercialization of semen of a polled bull produced using GnEd techniques by Recombinetics (USA) and Agropartners 
(Brazil). CTNBio analyzed and approved the GnEd cattle as non-GMO in October 2018. However, after the U.S. Food and Drug Administration analyzed the genome sequence of the bull in 2019 and unexpectedly found transgenic plasmid DNA sequences, the animal was then considered to be a GMO under Brazilian regulations. While the presence of the specific transgene or plasmid sequence in the genome of this GnEd animal was unlikely to pose a food safety concern, it would make the animal transgenic, and Recombinetics and Agropartners withdrew the application for further consideration by Brazilian regulators.

From the developers' viewpoint, GnEd offers flexible, fast, relatively inexpensive tools, which are potentially accessible to a broader range of developers. However, the success of the technology for agricultural animal applications will depend on the expense of passage through regulatory systems (Nesbitt 2020). To foster innovation, regulatory systems must: (1) ensure animal health and welfare, food safety, and environmental health, (2) be science-based and riskproportionate, (3) have clear, transparent processes and evaluation criteria with predictable timelines, (4) allow animals to be treated as conventional farm animals, and (5) be globally aligned. If regulatory systems do not meet these criteria, the consequences may include movement of R\&D activity and commercialization to countries with more amenable regulatory regimes (Fig. 2). For example, Van Eenennaam et al. (2019) termed the proposed U.S. animal drug regulatory approach for GnEd food animals as "not fit for purpose", and Ledford (2019) cited examples of American developers of GnEd animals moving their work elsewhere. Hess (2019) described Argentina, Brazil and Canada as outpacing United States in development of genome-edited animals.

\section{Environmental safety aspects of regulations}

\section{Environmental risk assessment}

A GM or GnEd animal will become incorporated into routine agricultural production only with demonstration that production can go forward in a safe manner in a particular environmental context. Environmental risk can be assessed and managed by applying the formal risk analysis process (Fig. 3, Andrade 2020), a general approach historically developed for epidemiological or chemical exposures that has been extended for application to GM plants and animals (Hilbeck and Andow 2004; Hilbeck et al. 2006; Kapuscinski et al. 2007; Roca et al. 2015). In the risk assessment context (NRC 1996, 2002), a harm is defined as an ecological perturbation resulting in negative impacts to a receiving ecosystem. A hazard is defined as an agent- the GM or GnEd animal-that has the potential to produce harm. Risk is defined as the likelihood of harm resulting from exposure to the hazard. Risk, $R$, is estimated as the product of the probability of exposure, $P(E)$, and the conditional probability of harm becoming realized given that exposure has occurred, $P(H \mid E)$. That is, $R=P(\mathrm{E}) \times$ $\mathrm{P}(H \mid E)$. The steps in risk analysis, then, are to: (1) identify the protection objectives; (2) identify hazards that might lead to harms in the context of protection objectives; (3) define what exposure means for a GM or GnEd animal and assess the likelihood of exposure, $P(E)$; (4) quantify the likelihood of harm given that exposure has occurred, $P(H \mid E)$; and (5) multiply the resulting probabilities to yield a quantitative estimate of risk. Exact probabilities of risk are difficult or impossible to determine for all types of possible harms. Indeed, it is unlikely that all possible harms would be known a priori, particularly for any indirect causal pathways, and quantitative estimation of $P(H \mid E)$ is difficult. Hence, it may be necessary to classify levels of concern regarding likely genetic impacts posed by production of GM or GnEd livestock into qualitative categories ranging from "low" to "high" (Table 2). For each identified hazard, the qualitative class of risk from "negligible" to "high" is determined by the likelihood of exposure or harm ("very low" to "very high") and the magnitude of the consequence ("marginal" to "major"). Usually only the negligible risks are considered acceptable.

Risk assessment (Fig. 3) involves both scientific and values-related considerations conducted within the context of interactions among a range of stakeholders (Andrade 2020). This involvement will bring all existing knowledge into the process, make the process transparent to stakeholders, and enhance the understanding and acceptance of the outcome of risk analysis. Stage I involves identifying the problems at hand, engaging stakeholders, identifying potential harms, risk pathways and assessment methods (Table 3). Stage II is the risk assessment itself, leading to estimating the likelihood that harm will become 


\section{As of 2 January 2021}

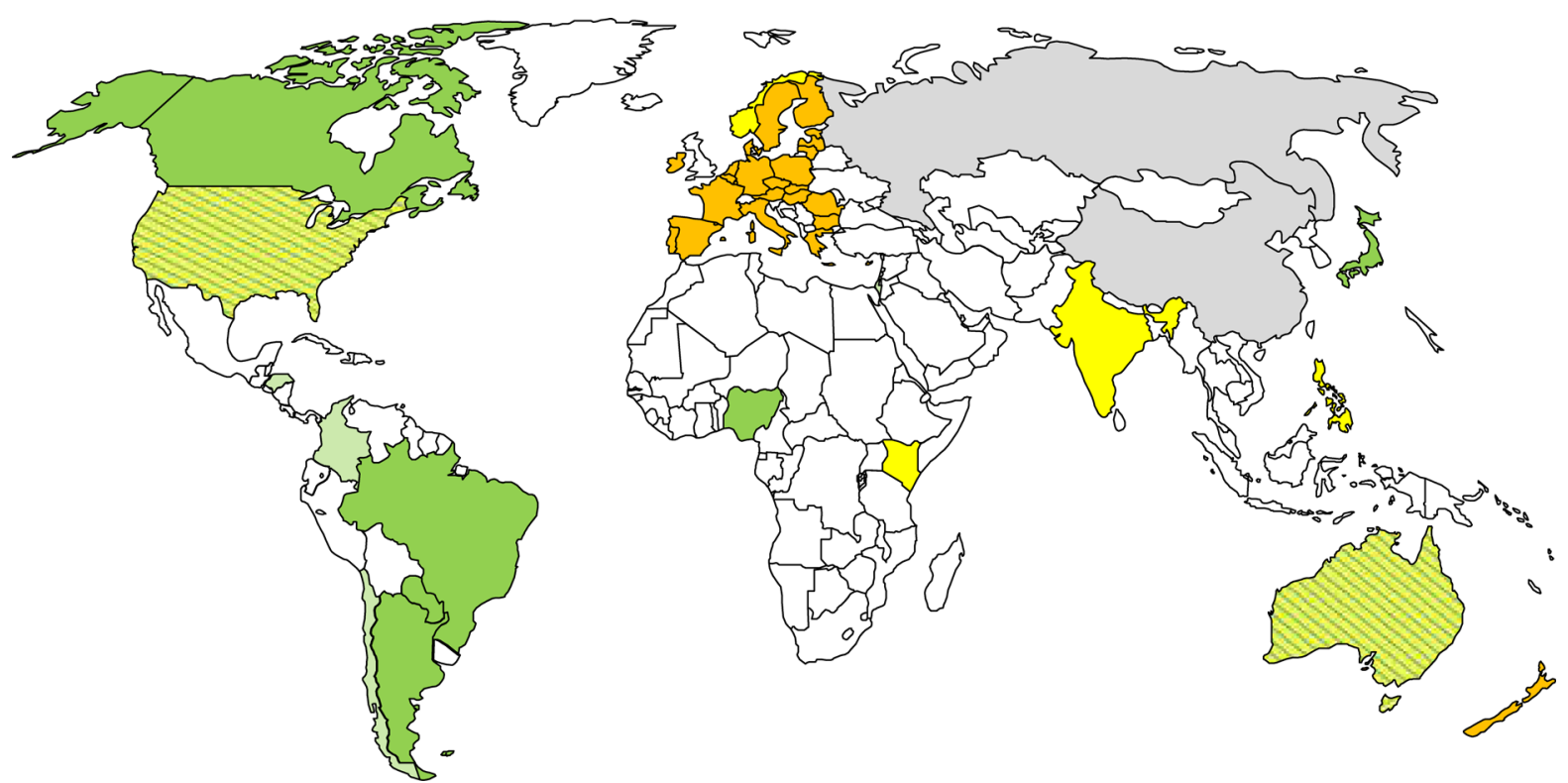

Countries with regulatory policy with exclusions

Countries with regulatory policy with exclusions (plants only)
Countries with pending policies, regulations, or legal rulings

Countries with GMO only policy with no exclusions

Fig. 2 Overview of national or supranational regulatory regimes for GM or GnEd animals

realized should a proposed action be taken. Upon estimation of that risk, a decision is faced as to whether the risk is acceptable. If it is acceptable, the decision may be made to go forward. If the level of risk is unacceptably high, risk management measures would be identified and residual risk quantified, and the decision of whether to go forward would again be considered.

\section{Regulatory approaches in different countries}

For oversight of environmental safety aspects of biotechnology, the most influential regulatory instrument is the Cartagena Protocol on Biosafety, an international agreement concluded and adopted under the framework of the Convention on Biological Diversity (CBD). The CBD is aimed at "ensuring safe transfer, handling and use of LMOs resulting from modern biotechnology that may have adverse effects on the conservation and sustainable use of biological diversity, also taking into account risks to human health, and focusing on transboundary movements" (Secretariat of the Convention on Biological Diversity 2000).

Under the Cartagena Protocol, an LMO (which is roughly equivalent to GMO in more common usage) means any living organism that possesses a novel combination of genetic material obtained through the use of modern biotechnology. "Modern biotechnology " is then defined as the application of: $a$. in vitro nucleic acid techniques, including recombinant deoxyribonucleic acid (DNA) and direct injection of nucleic acid into cells or organelles, or $b$. Fusion of cells beyond the taxonomic family, that overcome 


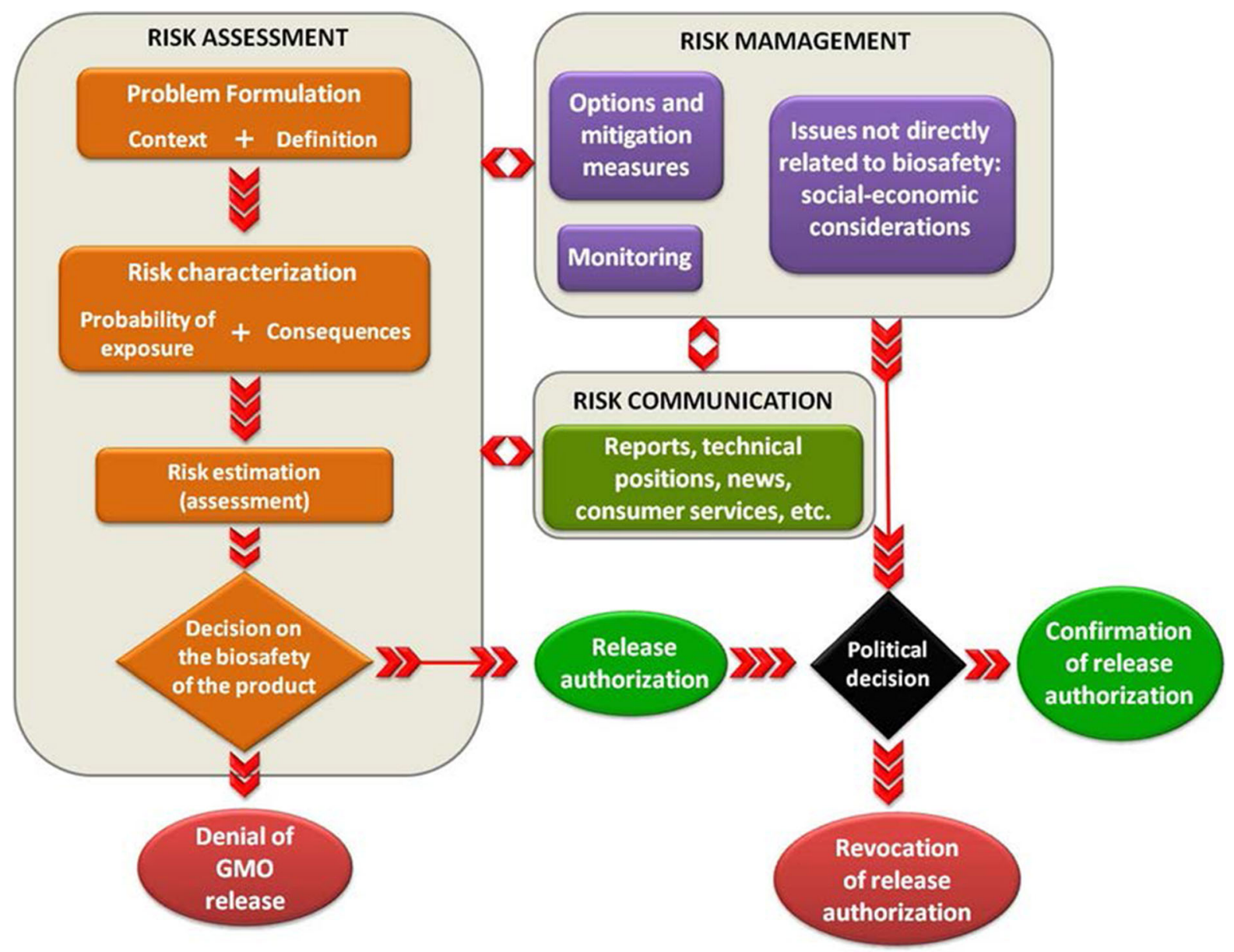

Fig. 3 An overview of the environmental risk analysis process (Roca et al. 2015; Andrade 2020)

Table 2 A qualitative approach to environmental risk assessment (Andrade 2020)

\begin{tabular}{|c|c|c|c|c|c|}
\hline \multirow{5}{*}{ 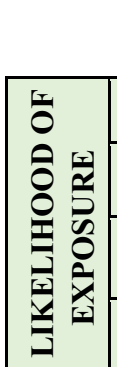 } & & \multicolumn{4}{|c|}{ CLASS OF RISK } \\
\hline & Very high & Low & Moderate & High & High \\
\hline & High & Low & Low & Moderate & High \\
\hline & Low & Negligible & Low & Moderate & Moderate \\
\hline & Very low & Negligible & Negligible & Low & Moderate \\
\hline & & Marginal & Minor & Intermediate & Major \\
\hline & & \multicolumn{4}{|c|}{ CONSEQUENCE } \\
\hline
\end{tabular}

The class of risk for each hazard, from negligible to high, is determined from the likelihood of exposure and magnitude of the consequence as defined by science

The yellow in the original version made clear that Consequence related to the Marginal, Minor, Intermediate and Major descriptors in the row above it 
Table 3 Framing of problem formulation for environmental risk assessment for three types of GnEd or GM animals in Brazil (adapted from Andrade 2020)

\begin{tabular}{|c|c|c|c|c|c|}
\hline Animal & Biodiversity protection goal & $\begin{array}{l}\text { Biology of } \\
\text { organism }\end{array}$ & $\begin{array}{l}\text { Receiving } \\
\text { environment }\end{array}$ & Gene construct & $\begin{array}{l}\text { History } \\
\text { of safe } \\
\text { use }\end{array}$ \\
\hline GnEd polled cattle & No obvious protection goal & $\begin{array}{l}\text { Non-native } \\
\text { No sexually } \\
\text { compatible } \\
\text { species } \\
\text { Dispersion } \\
\text { under control } \\
\text { Moderately } \\
\text { invasive } \\
\text { Not relevant } \\
\text { for wildlife } \\
\text { food chain }\end{array}$ & $\begin{array}{l}\text { Agricultural } \\
\text { systems }\end{array}$ & $\begin{array}{l}\text { CRISPR/CAS9 } \\
\text { leading to gene } \\
\text { silencing }\end{array}$ & $\begin{array}{l}\text { To some } \\
\text { extent, } \\
\text { yes }\end{array}$ \\
\hline GM fast-growing tilapia & Native river species & $\begin{array}{l}\text { Non-native } \\
\text { No sexually } \\
\text { compatible } \\
\text { species } \\
\text { Dispersion } \\
\text { under poor } \\
\text { control } \\
\text { Very invasive } \\
\text { Relevant for } \\
\text { wildlife food } \\
\text { chain }\end{array}$ & $\begin{array}{l}\text { Ponds, rivers } \\
\text { and lakes }\end{array}$ & $\begin{array}{l}\text { Transgene } \\
\text { constitutively } \\
\text { expressing a } \\
\text { growth hormone }\end{array}$ & None \\
\hline $\begin{array}{l}\text { GnEd snail for gene drive- } \\
\text { mediated population } \\
\text { suppression of an invasive } \\
\text { population }\end{array}$ & $\begin{array}{l}\text { No obvious protection objectives, } \\
\text { unless it does not function as } \\
\text { expected: if so, then native river } \\
\text { species }\end{array}$ & $\begin{array}{l}\text { Non-native } \\
\text { No sexually } \\
\text { compatible } \\
\text { species } \\
\text { Uncontrolled } \\
\text { dispersal, } \\
\text { very invasive } \\
\text { Not relevant } \\
\text { for wildlife } \\
\text { food chain }\end{array}$ & $\begin{array}{l}\text { Agricultural } \\
\text { areas }\end{array}$ & $\begin{array}{l}\text { Gene-drive } \\
\text { construct for } \\
\text { male-only } \\
\text { phenotype/ } \\
\text { fluorescence }\end{array}$ & $\begin{array}{l}\text { None for } \\
\text { snails }\end{array}$ \\
\hline
\end{tabular}

natural physiological reproductive or recombination barriers and that are not techniques used in traditional breeding and selection. These definitions were developed during the time when classical GM organisms were at issue; their relevance to GnEd animals is unclear. The applicability of the framework to different classes of modified organisms is still under discussion, particularly regarding clarification of the scope of regulatory definitions and international harmonization of regulations. In the meantime, some countries have adopted regulatory approaches similar to that embodied in the Cartagena Protocol (Argentina,
Brazil, Chile, Colombia, Honduras, and Paraguay). Some countries offer official scientific advice similar to the Cartagena Protocol (Kenya, Nigeria, and South Africa). Some countries have regulatory pathways that yield similar end results for most SDN1 GnEd animal products (Australia, Canada, and Japan). Some countries are bound by court decisions contrary to official scientific advice and national regulatory decisions (European Union and New Zealand). Not all countries are signatories of Cartagena Protocol on Biosafety, notably Argentina, Australia, Chile, Canada, and United States. Table 4 presents an overview of how 
individual countries and the European Union have instituted regulatory approaches incorporating environmental risk assessment of GM and GnEd animals. With its departure from the European Union, the United Kingdom is considering new policies to make it easier to test and commercialize GnEd crops and livestock (Stokstad 2021). Additionally, the African Union InterAfrican Bureau for Animal Resources (AU-IBAR) is promoting regulatory cooperation and development of harmonized guidelines among its member states (Nengomasha 2020).

While particular policy approaches differ because of differing institutional structures and regulatory histories, they share key similarities of technical approach. Case studies of national environmental regulations illustrate contrasts among regulatory processes and sometimes also for treatment of GM versus GnEd animals. In Argentina (Boari 2020), the Secretariat of Food, Bioeconomy and Regional Development within the Ministry of Agriculture, Livestock and Fisheries is the national authority for activities involving GM animals. The Secretariat is advised by CONABIA (National Advisory Commission on Agricultural Biotechnology), SENASA (National Service for Agrifood Health and Quality) and the Undersecretary of Agricultural Markets. CONABIA carries out the environmental risk assessment for confined activities or commercial release. CONABIA members are scientists, professionals, and specialists from different institutions, both from the public and private sectors. The goal of the environmental risk assessment (ERA) is to protect biodiversity, human and animal health, and the agroecosystems. CONABIA bases its evaluation on principles of formal risk analysis. The ERA for GM animals is flexible and applied on a case-bycase basis; data must be of sufficient quality and quantity and based on scientific criteria, with assessment of risk based on use of a suitable conventional counterpart. CONABIA conducts environmental risk assessment, SENASA assesses food safety, and the Undersecretary of Agricultural Markets performs economic evaluation and assesses the impact on foreign trade. The three institutions submit a nonbinding advisory report, recommending allowing or denying the proposed activities, after which the Secretariat grants or denies the authorization. For proposed confined activities, the facility's biosafety conditions are assessed with the intent of maintaining a safe environment during and after the project, preventing mating outside the project, avoiding animals escaping, and keeping them from entering the food chain or commercialization. Cases presented for confined activities in Argentina since 2005 have included GM fish expressing a growth hormone transgene for human consumption and cattle and sheep with altered milk composition for biopharming or human consumption. For commercial release, additional consideration is given to protection of biodiversity, human and animal health and agroecosystems. There have not yet been requests for commercial release of GM animals in Argentina.

In Brazil (Garcia 2020b), CTNBio in 2016 recognized the need to evaluate New Breeding Technologies, framed upon the legal definitions in Article 3 of Brazilian Biosafety Law 11.105/2005, the Biosecurity Act. Normative Resolution No. 16-Técnicas Inovadoras de Melhoramento Genético recognizes new methodologies that differ from classical genetic engineering that result in the absence of recombinant DNA/RNA in the final product. The regulatory process begins with a consultation letter, which presents descriptions of the parental and product animals and description of the technique(s) employed, which are used to determine the legal framework for the product. The determination is made of whether the new product is a GMO subject to Brazilian Biosafety Law 11.105, or not, for which non-GMO regulations apply. The analysis is carried out on a case-by-case basis, with attention to off-target effects upon the host, and extra precaution for cases involving gene drive. Under Normative Resolution $\mathrm{N}^{\circ} 16$, the first cases approved as non-GMOs included some yeasts, polled cattle (although the application was later withdrawn) and fast-growing Nile tilapia.

Regulation of animal biotechnology in New Zealand (Strabala 2020) goes forward under the Hazardous Substances and New Organisms Act of 1996. All organisms not present in New Zealand before 29 July 1998 are regarded as "new" organisms, including all GMOs. Under the Act, a GMO is any organism in which any of the genes or other genetic material: (a) have been modified by in vitro techniques; or (b) are inherited or otherwise derived, through any number of replications, from any genes or other genetic material which has been modified by in vitro techniques. Different release pathways are applied for importation into containment for GMOs that will not be further modified, development in 


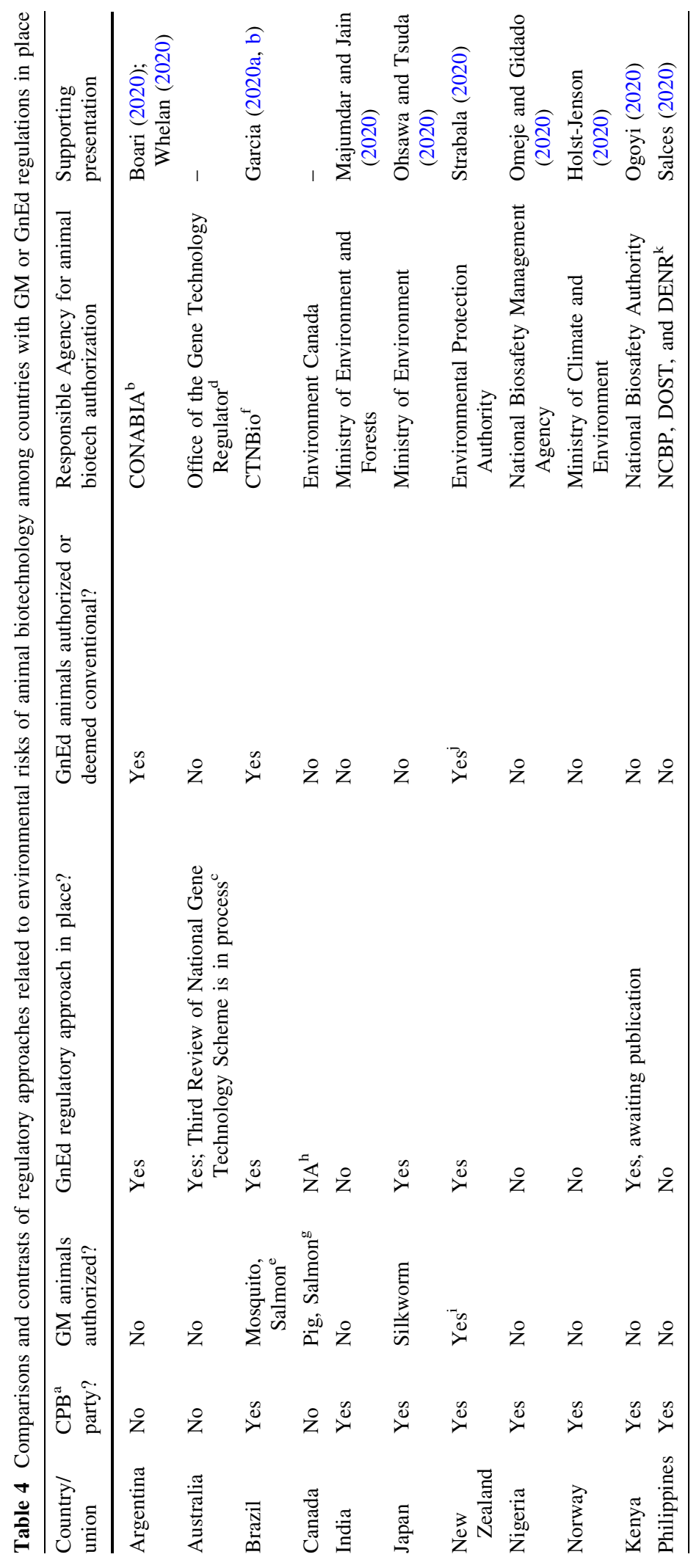




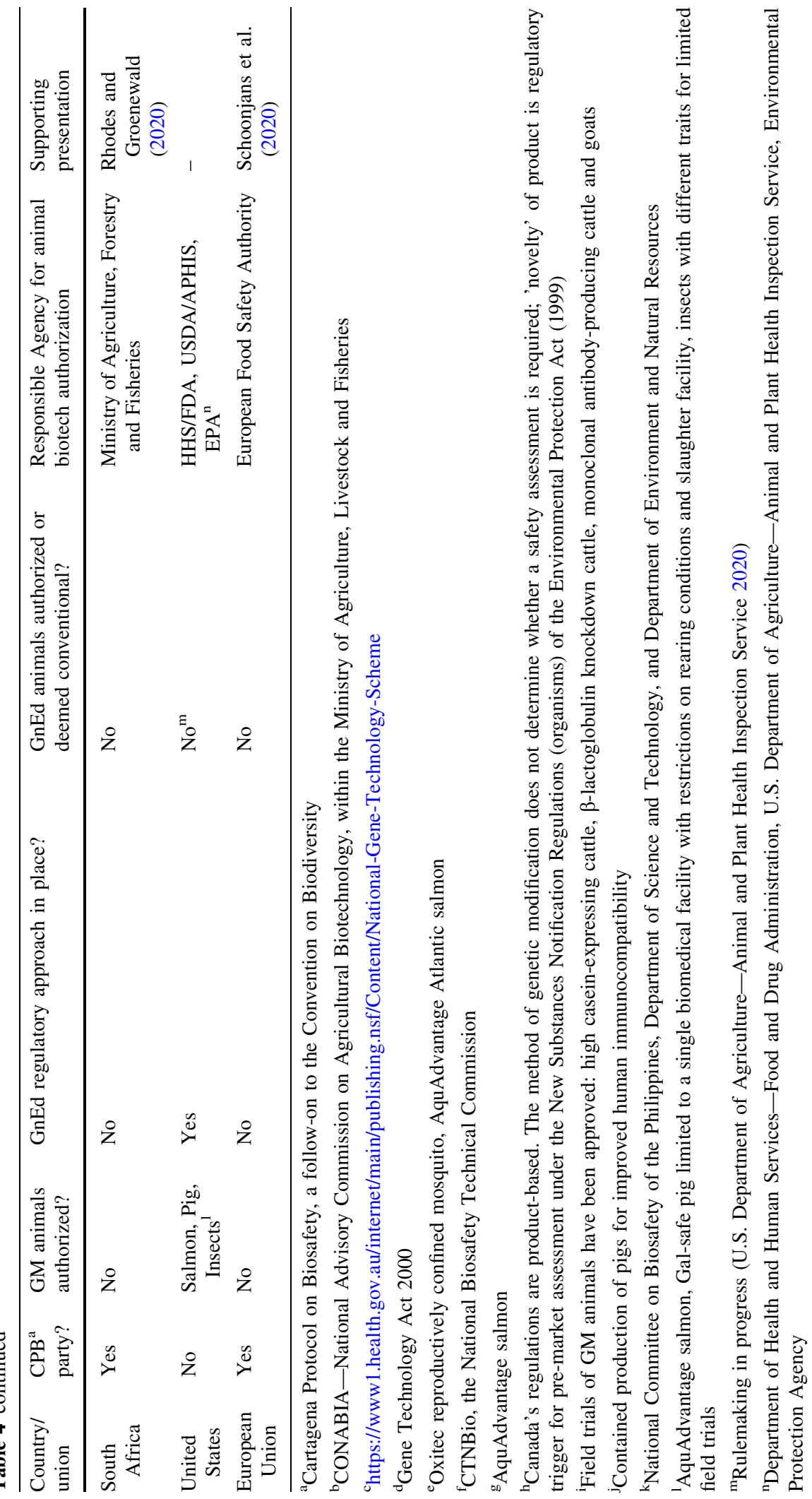


containment for creating new GMOs, field trial in containment, and release with or without controls. Actions under any of these release pathways must meet Sect. 36 Minimum Standards. That is, the Environmental Protection Authority (EPA) would decline the application if the new organism is likely to cause significant displacement of native species in natural habitat, significant deterioration of natural habitats, significant adverse effects on human health and safety, significant adverse effect to New Zealand's inherent genetic diversity, cause disease, be parasitic, or become a vector for human, animal, or plant disease. The EPA takes into account all information presented to it, including all public submissions and statements at hearings, and evaluates the benefits of the release against the risks. Current outdoor uses of GM animals in New Zealand include field trials of GM cattle overexpressing casein in milk and with knockdown of lactoglobulin to yield hypoallergenic milk. Genome editing technologies are considered as creating GMOs, per regulatory changes made in 2016. Approval has been given for the development of $\mathrm{GnEd}$ Auckland Island pigs in indoor containment for improved human immunocompatibility.

\section{Moving towards the market and public and consumer acceptance}

Public acceptance

The commercial success of GM and GnEd animals will depend upon public and consumer acceptance. Five key lessons can be taken from public attitudes to using genetically modification in animals in our "posttruth, post-trust, post-expert world" (Cormick 2020): (1) With the passage of time, attitudes regarding GM animals are becoming much closer to those for GM foods generally, with a lessening of high concern, and with younger people more accepting than older people. (2) Public attitudes fall into four segments ranging from highly supportive to highly unsupportive; many of the latter segment will likely never accept GM animal products. (3) The two middle segments defined as "Yes, but..." and "No, however..." are open to changing their minds and will determine what information should be shared to address public concerns. Public attitudes are best understood by analyzing these two groups. (4) Emotional attitudes are generally not driven by facts and logical arguments. (5) Trust is vital when information is contested; only $10-20 \%$ of the population is well informed on biotechnology, and most people go to social and mass media for information.

Important differences between expert and citizen perceptions of risk will affect the adoption of animal biotechnology (Frewer et al. 2016, Frewer 2020). Experts rely on technical risk assessments and use scientific argumentation, and generally do not take account of socio-economic impacts. Experts tend to balance risk against benefits, although it is not always clear how socio-economic or even technical benefits are assessed. In contrast, members of the public tend to use risk perceptions to make judgements about risk. Hence, effective risk communication must address their concerns as well as technical risk estimates. Emotional responses, as well as moral and ethical assessments, color public perception of animal biotechnology. The public wants to place trust in regulators. A meta-analysis of consumer attitudes to GM foods (Frewer et al. 2013) showed that plantrelated, "general", or biomedical applications were more acceptable than food animal-related applications. Risk perceptions associated with both plants and animals were greater in Europe than North America and Asia, while benefit perceptions were greater in North America and Asia than Europe. Moral concerns were higher in North America and Asia than in Europe. While the concerns expressed were very similar for both GM and GnEd, the motivation for applying breeding technologies was a key issue. Financial gain was not highly valued, while improved animal health, reduced negative environmental impacts, and human health were. This observation suggests a potential "tipping point" for acceptance of GnEd animals, for example, polled cattle.

Consumer perceptions of animal biotechnology in agriculture have largely proven negative, often not because of the technology itself, but rather because of what the technology represents. That is, expert and regulatory communications about GMOs have mostly been devoid of mention of values that align with those of consumers (Moore 2020). Shared values are 3-5 times more important to building trust than sharing facts or demonstrating technical expertise. Shared values regarding agricultural biotechnology would include: benefits to consumers and providing healthy, affordable food, not farmer benefits or profit; benefits 
to animals by improving animal health, not increasing productivity; and benefits to the environment, not increased efficiency. Hence, scientists, companies, and government officials should express such universal values in their messaging. For example, a message on PRRS-resistant pigs that "pigs that are resistant to one of the deadliest, incurable swine diseases will suffer less and fewer will die prematurely" is more effective than "modifying pigs to be disease-resistant increases profitability". Regulators have an important role in the conversation regarding GnEd; $50 \%$ of consumers trust what regulatory authorities say about $\mathrm{GnEd}$, and $63 \%$ trust regulatory authorities to explain the science regarding safe food production.

Greater attention should be directed towards understanding public perception of particular applications; an informative case study was conducted by Australia's Commonwealth Scientific and Industrial Research Organisation (CSIRO) regarding public perceptions of applying biotechnology to prevent the culling of male chicks in the egg-laying sector of poultry production. CSIRO's Synthetic Biology Future Science Platform (2020) engaged a sample of 1148 Australian residents in a survey of attitudes pertaining to the set of issues. Over 600 respondents had no awareness that male chicks were culled in the egg-laying industry, and approximately 900 viewed culling as problematic. Most respondents expressed belief that the new technology would reduce or eliminate the culling of male checks and perceived the advantage of biotechnology biology over the current practice. There was moderate to high support for the development of the technology and strong willingness to purchase eggs laid by hens involved in this process. Concerns were expressed regarding tampering with nature and unforeseen circumstances. Respondents felt that the science community should engage the public transparently, respectfully, and focusing on problem-solving as opposed to promoting biotechnology.

\section{Building trust for modern biotechnology}

As noted above, regulatory systems with clear, transparent processes have important roles to play in garnering public trust and fostering innovation in animal biotechnology (Gallo 2020). For example, the Brazilian regulatory process embodies transparency to build public trust (Dagli and Camargo 2020). The key body is CTNBio, a multidisciplinary biotechnology oversight commission created under Brazilian law in 1995 and renewed in 2005 under Biosafety Law 11.105 to provide technical support and advice to the federal government regarding formulation, updating and implementation of the National Biosafety Policy on GMOs. CTNBio is comprised of 27 Ph.D.-level professionals, including 12 subject-area specialists from outside of government, six subject-area specialists from government ministries, and nine representatives of government ministries (http://www.ctnbio. gov.br). All agendas, minutes, and activities for monthly CTNBio meetings are made available to the public. Meetings are open for attendance by registered members of the public. The CTNBio president and members have appeared in a variety of media outlets to discuss GMOs, GnEd, and new products that are released for commercialization. CTNBio meets regularly with the scientific community to promote transparency with researchers. While the question remains whether transparency is enough to build public trust and there have been some chaotic public meetings, applications of animal biotechnology are being adopted in Brazil to a greater degree than in other countries.

\section{Market readiness}

Adoption of animal biotechnology will depend upon the readiness of all participants in the value chain from producers to farmers to distributors, collectively the market. The readiness of the market will vary among regions.

Noting that farmed Atlantic salmon has a large international market with an inefficient supply chain, AquaBounty cites the environmental benefits of producing GM salmon in indoor recirculating systems near key markets. Their consumer research (Walton 2020) shows that $53 \%$ of respondents' first impression of GMOs related to food are neutral to very positive, $60 \%$ are neutral to very likely to purchase products they buy regularly if labeled as GMO, $70 \%+$ are neutral to very likely to purchase products that they buy regularly if labeled with the U.S. Department of Agriculture bioengineered disclosure symbol, $81 \%$ reacted as neutral to very positive to the AquaBounty and AquAdvantage story and product attributes or benefits, and $70 \%$ are likely to purchase and try AquAdvantage salmon at least once. These results 
suggest that the U.S. market is ready for marketing of this particular GM product.

South America presents an interesting perspective on market readiness for animal biotechnology (Garcia 2020a, b). Classical animal assisted reproductive technology methods (e.g., artificial insemination, embryo transfer, in-vitro fertilization, cloning), are well accepted and adopted if they are economically sustainable. GM livestock was not at issue, and there was no major public awareness of biotechnology by stakeholders until Acceligen's GnEd myostatin and polled cattle reached the point of concept discussion in 2013. Regulators-notably CTNBio in Brazil and CONABIA in Argentina-had designed and implemented case-by-case evaluation methodologies and reached regulatory landmarks for these cattle traits around 2018, and for GnEd Nile tilapia in 2019-2020. South American breeders and developers are keen to test the technology and evaluate its economic and commercial sustainability. The posture of activists and consumers in the region is largely unknown, however, and outreach to the general public, politicians, and social organizations would be timely.

\section{Summary of workshop breakout sessions}

During two of the virtual workshop sessions, we held fourteen breakout group discussions with researchers, developers, regulators, and young professionals within regions (e.g., Europe and North America, Asia and Oceania, Latin America, and Africa) to discuss challenges and opportunities. Key points recognized across all groups included a need for improved communication by scientists and regulators to build public trust and science-based modernization of regulatory policies that do not prove restrictive to academic researchers and small developers.

\section{Communication}

Livestock producers are tentatively interested in applications of $\mathrm{GnEd}$ that can improve production or efficiency but are concerned about uncertainties regarding the cost of bringing products to market and past public aversion to some technologies. For example, recombinant bovine somatotropin (rBST), a hormone injected into dairy cattle to increase milk production and approved by the FDA as safe in 1993
(U.S. Food and Drug Administration 1993, 2021), was rapidly adopted by much of the dairy industry and then subsequently abandoned due to consumer concerns. In this case, the public did not perceive sufficient benefits from the use of rBST to counter health and animal welfare concerns, and anti-biotechnology campaigns and misinformation were not effectively countered. Consumer acceptance of new biotechnology products clearly requires effective communication and consumer benefits, rather than only producer benefits as would be realized by some GM products.

Not all applications of animal biotechnology and GMOs are unpopular with consumers. For example, GM animals modified for pharmaceutical production have wide public acceptance in nearly all regions and have received regulatory approval in the European Union, the United States, and other countries (U.S. Food and Drug Administration 2009; Kling 2009; van Veen et al. 2012; Anonymous 2014; Shirley 2015). GloFish ${ }^{\circledR}$ offers several species and lines of fluorescent GM aquarium fishes that are popular aquarium pets in the United States and Canada (www.glofish. com), accounting for about $15 \%$ of all pet fish sales in the United States, although a recent poll (Pew Research Center 2018) found GloFish at the bottom of the list of GM animals supported by U.S. consumers. Further, plant-based meat substitutes created using GM yeast developed by Impossible Foods and other producers are increasingly popular with consumers who are vegetarians as well as those who normally eat meat but are concerned about environmental impacts and animal welfare. In the case of pharmaceuticals and meat substitutes, there are clearly communicated consumer benefits-life-saving drugs that are not easily produced by other methods and food sustainability. GM animals lacking a clear consumer benefit face broader resistance from consumers and environmental groups.

Communicating consumer benefits of animal biotechnology was recognized by all regional discussion groups as an area needing greater attention. As noted, scientists enjoy explaining the technical aspects of biotechnology, but do not always effectively convey societal benefits. Non-scientists are generally not interested in genetic mechanisms or increases in efficiency benefiting producers but are more receptive to outreach if their concerns are directly addressed. For example, a narrative about improved efficiency to reduce greenhouse gas emissions may be better 
received than one on production efficiency. Recommendations included training for scientists to engage in active societal dialogue, not just to teach the science. Training programs in science communication exist for students and are increasingly viewed as important. Many scientists are already highly effective communicators, yet are limited by time, resources, and funding. Public communication requires incentives, such as funding and institutional support. Finding the right balance between research and public outreach is an ongoing challenge.

There are several GM and GnEd animals that are being developed to specifically address consumer values and producer needs. Many animals that have been developed with the potential for commercialization have traits centered on animal and worker welfare, rather than traits solely for production costs, taste, or nutrition. For example, pigs modified to be resistant to porcine reproductive and respiratory syndrome will not suffer or be lost due to the disease. Dairy cattle modified to have the polled allele will have to not undergo the painful practice of disbudding. Comparatively, producing the hornless trait in dairy cattle using conventional breeding would take many generations, with significant losses in production. The environmental impact of meat production is gaining public awareness, particularly regarding greenhouse gas emissions. Public support might be gained by framing GnEd as a way to quickly reduce environmental impacts through improved efficiency in ways not possible with conventional breeding.

An example of a GM animal that meets consumer demand in a very specialized niche market and not focused on producer needs is the GalSafe pig, a GM pig engineered to eliminate the alpha-gal sugar on cell surfaces. This GM animal was developed for biomedical applications, such as xenotransplantation and porcine-derived drug products like heparin that are free of detectible alpha-gal. Given the rise in certain red-meat allergies, the company also sought approval for food use. While the U.S. Food and Drug Administration did not evaluate the allergenicity and food safety of this product for people with Alpha-gal syndrome (AGS), an allergy to red meat resulting from a Lone Star tick bite, since the product is free of detectible alpha-gal sugars, it should allow people with this allergy to safely consume this pork (U.S. Food and Drug Administration 2020). This GM pig, however, is quite restricted regarding rearing conditions and is not approved for production on conventional farms. Therefore, it fits into an unusual category of a GM trait that only serves to benefit consumers with AGS, without conveying any benefit to farmers.

How the distinction between GM vs GnEd products may affect consumer acceptance is not certain. Precise edits of single nucleotides or the addition of a trait from the same species, equivalent to what could be achieved through conventional breeding, may be more acceptable to consumers if clearly communicated. Genes inserted from other species will likely continue to face increased scrutiny. The regulatory approaches of some countries have tiered oversight, with different assessment requirements for these different changes. As noted above, some countries are taking different approaches to regulating GM and GnEd animals, which will both influence and be influenced by public perception.

\section{Regulatory approval}

Regulatory approval is a long and uncertain process in many countries, and regulatory uncertainty is a significant concern to both developers and academic researchers. The experience of AquaBounty, with a 20-year regulatory and public acceptance pathway, has led to hesitancy among companies to invest heavily in animal biotechnology. Animal agricultural companies are awaiting examples of successful applications to pave the way for public acceptance. The regulatory landscape for animal biotechnology is continuing to evolve globally, with growing distinction between classical genetic modification using rDNA and more recent GnEd approaches used to generate changes that could occur through mutagenesis or conventional breeding.

Unnecessary costs associated with non-risk-based regulatory frameworks may limit developments. Regulatory frameworks in some countries are costly and difficult to navigate, and can prove prohibitive to innovation, especially for academics and small companies developing technology. Public policies directly affect the choice of research topics. For example, basepair and gene deletions are easier to gain approval for through regulatory pathways than insertions, and thus research focuses on developing new traits through deletions. In Canada, proponents must put an economic value on a trait, which means that only highvalue traits are targeted. In several countries, there are 
two or more agencies involved in the approval of a product. For example, in Australia food safety approval (conducted by FSANZ) is distinct from approval of the animal for commercial release (conducted by the Office of the Gene Technology Regulator). In Canada, it was recommended that a food safety evaluation be done for a GnEd animal although not required, as the trait was not novel, to "make the public more comfortable." Of great concern to developers, breeders, and scientists are the lost opportunity costs-every year that existing technology is not used means avoidable costs in terms of disease prevention, animal welfare, and global food security (Van Eenennaam et al. 2021).

Public trust in regulatory approaches and decisions is critical. Regulations may enable public trust by reassuring the public that products are safe, but also may generate safety concerns unsubstantiated by science (i.e., "if this is safe, then why is it so strictly regulated?"). Likewise, how the product is regulated-e.g., as an animal drug or as a food animal may alter consumer perception of safety in different ways. This may be particularly confusing in the United States because a single nucleotide deletion in plants is exempt from biotechnology regulation, yet the same type of edit in an animal is regulated as a drug. Further, perception of agricultural biotechnology is also closely tied to negative perceptions of large corporations. Ironically, as seen most clearly with the plant biotechnology sector, ${ }^{1}$ the costly regulatory process allows mainly large corporations to gain approval of their products and limits commercialization of products developed by the academic or public sectors and small businesses, as well as limiting the type of traits developed (Whelan et al. 2020). This situation likely compounds public mistrust of such corporations and increases mistrust of the products at issue. Developers suggested that regulations should be streamlined so that small firms and academic institutions also can afford the approval process and thereby shift GM and GnEd products from the association with large corporations. Overall, science-based regulatory development and modernization was recognized as a critical issue for moving animal biotechnology forward.

\footnotetext{
${ }^{1}$ There is only one GM animal developed for food use on the market; therefore, it is necessary to look to the plant biotechnology sector for examples and analysis of impacts of regulatory approaches.
}

Marketing and trade

As countries continue to develop regulations, sharing guidelines and experience is key to encouraging harmonization to enable international trade. Currently, variation among regulatory systems and regulatory uncertainty have limited international trade of animal biotechnology products in several regions. Moreover, differences in definitions make tracing products of biotechnology, when required, challenging and expensive. New products will likely have to be accepted on a market-by-market basis as regulatory approaches and frameworks develop. The challenge of regulatory approval has caused companies to avoid pursuing marketing in some regions, while at the same time still engaging with regions that have a large influence on global developments (e.g., the European Union). Often developers will delay the commercialization of new products until export is possible into major markets, as demonstrated in the seed industry, where seeds for new approved crops are not released until approvals in key markets are obtained, delaying farmer access to new traits. Mutual recognition of regulatory decisions would facilitate trade and encourage innovation. There is some alignment of regulatory processes among South American countries.

Labeling presents a particular challenge for trade of products from GnEd animals that do not have new DNA sequences or edits that distinguish them from conventionally-bred animals. The need for labels based on process when two products cannot be distinguished was questioned by researchers and developers. Already a lot of information that could be provided on labels is not (e.g., cattle breeds, antibiotic use), even when consumers may care about these characteristics. Part of the challenge is to avoid misleading consumers with labels when the meaning to the public is not clear. The objective of the label needs to be critically evaluated. In some cases, labeling products of GnEd could be beneficial if the product develops a reputation for sustainability or improved safety and may occur voluntarily, although this is far from certain.

Marketing and trade require some degree of agreement or mutual understanding relative to regulatory processes among trading partners. With GM products developed with rDNA insertion, the regulatory processes and timelines are not harmonized globally, resulting in asynchronous approvals. 
However, historically there has been general agreement among most countries regarding the definition of rDNA-derived plants and animals and what types of products are regulated. One major challenge with lack of harmonization of regulatory approaches for products of GnEd could be that different countries will make differing determinations as to the types of GnEd products that are regulated as conventional products versus those that will be regulated under their GMO regulations.

\section{Regional aspects}

Much trade, research, and animal selection occur within regions. Because most livestock trade occurs within regions, we consider the development of animal biotechnology policy and related issues within selected regions.

African researchers using GnEd could provide solutions appropriate to regional needs. For example, non-adapted but highly productive cattle breeds could be edited to express the necessary drought, heat, and disease resistance traits required in Africa, to rapidly improve food security and reduce the environmental impact of cattle production. While these results could be achieved using conventional backcross breeding, the time required to achieve large-scale outcomes is unaffordable. Before GnEd can be employed, issues of training, funding, and access to technologies must be resolved. Moreover, African countries are challenged by fragmentation of capacity in the public sector and low acceptance of biotechnology. Currently, Kenya, Nigeria, and South Africa are most actively involved in developing regulatory approaches regarding products of GnEd.

With the exception of Japan (Tsuda et al. 2019), regulations for GM and GnEd animals in Asia are under development, pending, or do not exist. In general, Asian countries face similar challenges of public acceptance, lack of research and development support, and technical expertise. Many countries lack experience in safety assessments of GM animals, clarity regarding regulatory pathways, public confidence in food safety of GM products, and public understanding of benefits of GM products. However, there is also considerable variation in public support and engagement among countries. For example, the Philippines has good and positive engagement with the public and stakeholders, with high levels of trust for safety in regulatory authorities. Regulatory harmonization, especially in environmental risk assessments, may be difficult to achieve because of the complexity and differences in environmental conditions and public perception.

In Central and South America, Brazil and Argentina have well-defined regulatory pathways for biotechnology, and though regulatory policies for GnEd animals are under development, the two countries are poised to lead the world in adoption of products of animal biotechnology. Both countries have made regulatory determinations for GnEd products, deeming products that do not contain "foreign" DNA as conventional. These two countries serve as an example to low- and middle-income countries with limited regulatory resources that are developing animal biotechnology regulations and regulatory approaches for products of GnEd. An increasing number of Latin American countries are aligning with Argentina and Brazil.

The United States and the People's Republic of China have large agricultural economies and both have invested heavily in development of agricultural biotechnology. Should they develop and implement policies enabling adoption of GnEd animals, due to their global economic impact, this would likely lead more countries to develop trade- and innovationenabling regulatory policies.

\section{Conclusion}

Many challenges remain for animal biotechnology to gain trust and acceptance and to become available for farmers to use to meet global demand for food products while improving animal welfare and reducing environmental impacts. Thoughtful communication can help consumers become aware of the benefits to themselves (e.g., food prices/availability, enhanced nutrition), animal welfare (e.g., reduction of diseases; cattle that will not need to be dehorned; pigs that will 
not need to be castrated), and the environment (improved efficiency reducing inputs and greenhouse gas emissions; aquaculture production reducing demand on natural fisheries and using fewer resources), as well as the costs of inaction (prevalence of preventable diseases, environmental costs). The degree of adoption of animal biotechnology will be determined by public perception and the development of regulatory approaches that are science-based and risk-proportionate. Many critics of animal agriculture and biotechnology emphasize the need to reduce or cease the use of animals due to environmental impacts and welfare concerns. These concerns are valid to some extent; however, demand for animal products will continue and will increase in some regions for the foreseeable future. Genome editing technology offers an opportunity to rapidly improve animal welfare and reduce environmental impacts that would otherwise be cost-prohibitive using conventional breeding and if not cost-prohibitive, could take decades to achieve.

The community of professionals that participated in the virtual workshops identified steps that might be taken to achieve the conditions needed for GM and GnEd animals to be used in practical applications in agriculture. Building human infrastructure is critical for effective regulatory oversight. Regions developing regulations need to train scientists on regulatory systems and communication, not only to support oversight of animal biotechnology and to create the next generation of regulators. Training is needed for assessing animal biotechnology, animal welfare, and food and environmental safety. Facilitating international dialogue and training is especially important in regions that are developing regulations. Continued communication between scientists, developers, breeders, farmers, regulators, and the public is necessary for all sides to build trust and transparency. Assisting journalists, teachers, and politicians in their understanding of the basics of biotechnology and value of its applications is essential. Workshops for training scientists in public communication, as well as regional and global workshops to disseminate information on research, regulations, and communication best practices, are ongoing or under development. Communication strategies must be designed for particular countries and regions based on the needs and concerns of the regional public. Regulatory alignment or compatibility and modernization of existing regulations are important to enable development and trade, while encouraging innovation. Regulatory alignment, at least within and among some regions, would reduce non-tariff barriers to trade that limit growth of the industry, particularly for smaller companies. Regional workshops and meetings will allow continuing information-sharing, especially of regulatory guidelines and case-studies of successful and unsuccessful applications.

Acknowledgements We gratefully acknowledge the contributions of the presenters and participants in the Virtual Workshop Series on Regulatory Approaches for Agricultural Applications of Animal Biotechnology. These workshops were the product of collaboration among the U.S. Department of Agriculture, ISAAA - the International Service for the Acquisition of Agri-Biotech Applications, IICA-the InterAmerican Institute for Cooperation on Agriculture, and Virginia Tech University and supported by agreements with the USDA Foreign Agricultural Service. JPB was supported by an AAAS Science \& Technology Policy Fellowship served at the USDA Office of the Chief Scientist. The manuscript was strengthened by attention to the comments of two anonymous peers and the editor-in-chief.

Authors' contributions Writing and original draft-EH, JB, LSC; Writing review and editing-all authors.

Funding The international workshop was supported by the U.S. Department of Agriculture-Foreign Agricultural Service.

Availability of data and material Supporting material may be found at: https://sites.google.com/a/vt.edu/ animalbiotechresources/2020-online-workshops.

\section{Declarations}

Conflict of interest Author Mark Walton is employed at a company commercializing a GM animal; all other authors are employed by academic, research, government, non-governmental organizations, or international cooperation agencies. Mention of any company or product is for informational purposes and does not represent endorsement by the U.S. Department of Agriculture. The findings and conclusions in this 
publication are those of the authors and should not be construed to represent any official USDA or U.S. Government determination or policy.

Open Access This article is licensed under a Creative Commons Attribution 4.0 International License, which permits use, sharing, adaptation, distribution and reproduction in any medium or format, as long as you give appropriate credit to the original author(s) and the source, provide a link to the Creative Commons licence, and indicate if changes were made. The images or other third party material in this article are included in the article's Creative Commons licence, unless indicated otherwise in a credit line to the material. If material is not included in the article's Creative Commons licence and your intended use is not permitted by statutory regulation or exceeds the permitted use, you will need to obtain permission directly from the copyright holder. To view a copy of this licence, visit http://creativecommons.org/licenses/by/4.0/.

\section{Glossary of terms}

CRISPR-Cas9 repeats) is a family of DNA sequences found in the genomes of prokaryotic organisms; derived from DNA fragments of bacteriophages that had previously infected the prokaryote, they are used by the host to detect and destroy DNA from similar bacteriophages during subsequent infections. Cas9 (or "CRISPR-associated protein 9") is an enzyme that uses CRISPR sequences as a guide to recognize and cleave specific strands of DNA that are complementary to the CRISPR sequence. Cas9 enzymes together with CRISPR sequences form the basis of the CRISPR-Cas9 vector that can be used to edit genes within organisms (Doudna and Charpentier 2014)
Environmental risk assessment (ERA)

Genome edited (GnEd)

\section{Living Modified \\ Organism (LMO) \\ Modern biotechnology}

Adjective, referring to an animal subject to classical gene transfer methodologies whereby an introduced recombinant DNA construct integrates randomly into the host genome, or to its descendants that inherit that construct

Adjective, referring to an organism in which a nuclease (such as zinc finger nucleases, TALENs, or CRISPR/Cas9) creates a change (insertion, deletion, or substitution) at a targeted site in the host genome

Any living organism that possesses a novel combination of genetic material obtained through the use of modern biotechnology (Secretariat of the Convention on Biological Diversity 2000)
Regulatory cooperation nucleic acid techniques, including recombinant deoxyribonucleic acid (DNA) and direct injection of nucleic acid into cells or organelles, or b. Fusion of cells beyond the taxonomic family, that overcome natural physiological reproductive or recombination barriers and that are not techniques used in traditional breeding and selection (Secretariat of the Convention on Biological Diversity, 2000)

The process whereby two countries or supranational entities work together to achieve a regulatory outcome in the absence of efforts to adopt similar policy structures 
Regulatory harmonization

SDN1 genome editing

TALENs

$\mathrm{ZFN}$, zinc finger nucleases
The process whereby two countries or supranational entities seek to establish similar regulatory policies produces a double-stranded break in the genome of a target organism without the addition of foreign DNA. The spontaneous repair of this break can lead to a mutation or deletion, causing gene silencing, gene knock-out, or a change in the activity of a gene

Transcription activator-like effector nucleases are restriction enzymes that can be engineered to cut specific sequences of DNA. They can be introduced into cells for use in genome editing Artificial restriction enzymes generated by fusing a zinc finger DNA-binding domain to a DNA-cleavage domain. Zinc finger domains can be engineered to target specific DNA sequences, enabling targeting of unique sequences within complex genomes. By taking advantage of the endogenous cellular DNA repair machinery, ZFNs can be used to precisely alter the genomes of an organism.

\section{References}

Abley M (2020) Food safety measures for conventional animals. https://752610ed-a-d8d7ceb9-s-sites.googlegroups.com/a/ vt.edu/animalbiotechresources/2020-online-workshops/ Abley-FSISRegulatoryAuthority.pdf?attachauth $=$ ANoY7 crpyJeVcVBTgsNBJ2XX2089ULDNcyIInINeNOEjU0 ZRTbTtcKV_uZFY_tfd0q8wpzsCgoJ0i40DP6eyBh0m MjvWunGa-tLv1fLDMaB1xLW-Nxd164MXWLYrnBM 8-R0nesZxw-J8gCREjbqCDFrEpRvyqDHPWeNmrEBE c-UrPTLU6gnm1Mb58MPVRq1OgDitISrkgH-dX8BOY rerD40fTX81JwZmZ7fzlU73gUxqfBsXN-e8y9KhUky

H1PfyRenuT5LHp8fB3iv997gIPlzeUdkSGKrew\%3D\% 3D\&attredirects $=0$.

Academy of Science of South Africa (2017) The regulatory implications of new breeding technologies. ASSAf, Pretoria. https://research.assaf.org.za/bitstream/handle/20. 500.11911/29/2017_\%20assaf_new_breeding_techniques. pdf? sequence $=5 \&$ isAllowed $=y$

Adams NR, Briegel JR, Ward KA (2002) The impact of a transgene for ovine growth hormone on the performance of two breeds of sheep. J Anim Sci 80:2325-2333

Alvarado C (2020) Food safety industry perspective. https:// 752610ed-a-d8d7ceb9-s-sites.googlegroups.com/a/vt.edu/ animalbiotechresources/2020-online-workshops/ Alvarado-IndustryFoodSafetyPerspective.pdf?attachauth= ANoY7cqEaiqXtF6B56hbNCbzDG7SSvhNcAj6 UgAqceFuxyj5x-UmNXHJnsENSK9QWCcCXcUlSOzw_ cm_oE3GGn-_yk7AmkNvxJCcXhcitib9I7kTeLXEeN1Tr-MKKIWWzGFTPwyMLB70oKpVWz64L6tjOE1J recBE9FUAgocsi_07AbvCUbenI3x_8cNu47JHph5gr16 heWc2Oei0GUIpp4vttz6RrWfAsVWniWO8k0N5asCjs T5HWg_hhreZA4e3gcX5SSOKkcOLBmNoKPLzft2 CkJa-9NtcRkZTeFnSztozelbTJCXKM\%3D\&attred irects $=0$

Andrade P (2020) Environmental risk assessment of GM and GE animals. https://752610ed-a-d8d7ceb9-s-sites.google groups.com/a/vt.edu/animalbiotechresources/2020-onlineworkshops/AndradeEnvironmentalRiskAssessmentGM andGEAnimals.pdf?attachauth=ANoY7coVVzTay3qpBH nUrr3hKU6mK5vvqqZ1J3wqXuitO1DtfqHsAZQF1Xabs auNI0AUI6NidZ7rezUgBLGNrvCKC7Rfumf4KMoam11 CsVq3LCJNbksr58gNhCNMb784c6L_yXxkay5uWQf1 RGuxDjt4JK1-EpQOdiSUvFFgBTrD1CTZzCLcZdS 8jqhkpeSP3zfv6GDbJPQc3Bu4X5tmLbgL1GCT8 GqpyDEYgPDlkzIFajAXIdZ8U0z5601T4-9GlpAsY5O a638m5YzRV-pmoqhKU4zi9UwwmidibgKu_fBUq4jaAnBBMY\%3D\&attredirects $=0$

Anonymous (2014) FDA approves second transgenic milk drug. Nat Rev Drug Discov 13:644

Asahi Shimbun (2021) Fleshier sea bream due to genome editing hits the market. Asahi Shimbun, September 30, 2021. https://www.asahi.com/ajw/articles/14445610

Bleck GT, White BR, Miller DJ, Wheeler MB (1998) Production of bovine $\alpha$-lactalbumin in the milk of transgenic pigs. J Anim Sci 76:3072-3078

Boari P (2020) Environmental safety aspects of regulations for GM animals in Argentina. https://752610ed-a-d8d7ceb9-ssites.googlegroups.com/a/vt.edu/animalbiotechresources/ 2020-online-workshops/BoariERAofGMAnimalARGEN TINA.pdf?attachauth=ANoY7cp 1 wespIrudCpg9yXp6w LIqrV-xR4k2vZIcweTO_aqBIDCGWggAQz9MhVSTPH cqJmV_sMabiun7nqEe5XuGaKTzcxw2nkpzk0SrJot_ oo3Jv1HyWiF7LsDkrZqzHPmWKj5f-00iUSe9RzIs-4AK 5RdJKwNyVaAPHuFyTsyXJxLWnyKrFhReOZwmPdLYvgrCpYWaRmfCorzx7BmhVBScs2UXme-Xjwy4jFffc FE_m2t54tQf-Sks2I_T9AfArIwtTFId3MIcYkr_xp3gN TkpG6sHiosUQ\%3D\%3D\&attredirects $=0$

Bratlie S, Halvorsen K, Myskja BK, Mellegård H, Bjorvatn C, Frost P, Heiene G, Hofmann B, Holst-Jensen A, HolstLarsen T, Malnes RS (2019) A novel governance framework for GMO: a tiered, more flexible regulation for GMO 
s would help to stimulate innovation and public debate. EMBO Rep 20(5):e47812

Brody S. (2020) Swine. https://752610ed-a-d8d7ceb9-s-sites. googlegroups.com/a/vt.edu/animalbiotechresources/2020online-workshops/BrodySwine.pdf?attachauth=ANoY7 cp4W1_WzXF19NW0HrTQdR0w-wRGd1trIudQ7Ttv1L dtFz_u2UTVJYoL6k4UeRrpBBCfG4KG521g6zdOyGm B8vz1ZLHm04h_-2Ez_aSxETZbTE4wpD8HzMo5kwH Fa4OWFoutHlegmxOeOR-KZnT9Ud4yTXOvAxdLsSJp vWrI3043RrdKAxBqpHF7bZ82_yiMaHu1ZGxogRLBg XKJILBGmqtsJ6vJLpsS36ieHPTIN7UFESxE38nMclgIvDulm_oHLPaa4c5\&attredirects $=0 \&$ revision $=1$

Burkard C, Opriessnig T, Mileham AJ, Stadejek T, Ait-Ali T, Lillico SG, Whitelaw CB, Archibald AL. (2018) Pigs lacking the scavenger receptor cysteine-rich domain 5 of CD163 are resistant to porcine reproductive and respiratory syndrome virus 1 infection. J Virol 92(16)

Camargo LSA, Owen JR, Van Eenennaam AL, Ross PJ (2020) Efficient one-step knockout by electroporation of ribonucleoproteins into zona-intact bovine embryos. Front Genet 11:570069. https://doi.org/10.3389/fgene.2020.570069

Carlson DF, Lancto CA, Zang B, Kim ES, Walton M, Oldeschulte D, Seabury C, Sonstegard TS, Fahrenkrug SC (2016) Production of hornless dairy cattle from genomeedited cell lines. Nat Biotechnol 34(5):479-481

Chandrasegaran S, Carroll D (2016) Origins of programmable nucleases for genome engineering. $\mathrm{J}$ Molec Biol 428(5):963-989

Cianciarelli G (2020) The regulation of animal biotechnology in Canada. https://752610ed-a-d8d7ceb9-s-sites.google groups.com/a/vt.edu/animalbiotechresources/2020-onlineworkshops/Cinciarelli-CanadaAnimalBiotechRegulations. pdf?attachauth=ANoY7coBLtkZOZYJA_DchR6LZ4v yobbnzBNbEth95PiPS_XeydLsJgrMddmogeOc1Jotes wrZWIuc0hOY5Ewd6Jm4gGOQTmD9FR5MdqNgw O4180PkN_QmsNxEy1zxs9nf57UaELYZM-uquwEy KZ6tNojW1_vBLcgIYT2aDzJotMBAIoupdc85oK2uviISuuDUcKibBtCdNpshgFKJokAx7yO26gpxxFH_t4okd 6WuRg9C-8aHpUx5fbwTA28-mHPmuBr-8pnI3NFIF Cpkp8YG3pSoGQdLUSTsUzyIRU_YGia1CSHme ZSCg\%3D\&attredirects $=0$

Cooper CA, Klobas LC, Maga EA, Murray JD (2013) Consuming transgenic goats' milk containing the antimicrobial protein lysozyme helps resolve diarrhea in young pigs. PLoS One 8(3):e58409

Cormick C (2020) Five key lessons from public attitudes to using GM in animals. https://drive.google.com/file/d/1iSpFKrNj5nJQhA3UHiZ34pU292AHlv4/view

Crispo M, Mulet AP, Tesson L, Barrera N, Cuadro F, dos Santos-Neto PC, Nguyen TH, Crénéguy A, Brusselle L, Anegón I, Menchaca A (2015) Efficient generation of myostatin knock-out sheep using CRISPR/Cas9 technology and microinjection into zygotes. PLoS One 10(8):e0136690.

Dagli MLZ, Camargo LS (2020) Regulators building public trust: the example of CTNBio, Brazil. https://752610ed-ad8d7ceb9-s-sites.googlegroups.com/a/vt.edu/animal biotechresources/2020-online-workshops/DagliCamargo RegulatorsBuildingPublicTrust.pdf?attachauth $=\mathrm{ANoY7}$ cpBd59-fwLex9km9C1w7S32MOQ1pnt3jpzr9QEqM3 RaK69buN-v1wHr4vesZWRDdh7qCUVDT0wbklGUYA
icoYafEPRvmCMyl6ra2MwqhUh_Dxv8NT1sWFQ1L sgsujWY_nEA3Rzuwhbt9V2XIpYEi_Teyp9dCmV27 WHhGzUyyRKKNhKlyWSm2Ccg3u3IyJgNHqnuR2E 0A2O7Vs66exjtMsKJs1aeLsEd_mC6gMymvej6EJZvvk WIX15qspC5T_Mnyojy7t0qpy4DlrLdkYItitv5ArT57B92i7wkDTaytfa3-u97_I\%3D\&attredirects $=0$

Damak S, Su HY, Jay NP, Bullock DW (1996) Improved wool production in transgenic sheep expressing insulin-like growth factor 1. Biotechnology 14:185-188

Donovan DM, Kerr DE, Wall RJ (2005) Engineering disease resistant cattle. Trans Res 14:563-567

Doran T, Challagulla A, Cooper C, Tizard M, Jenkins K (2016a). Genome editing in poultry-opportunities and impacts. Natl Inst Biosci J 1. https://doi.org/10.2218/ natlinstbiosci.1.2016.1742

Doran TJ, Cooper CA, Jenkins KA, Tizard MLV (2016b) Advances in genetic engineering of the avian genome: "Realising the promise." Transgen Res 25:307-319. https://doi.org/10.1007/s11248-016-9926-8

Doudna JA, Charpentier E (2014) Genome editing. The new frontier of genome engineering with CRISPR-Cas9. Science 346(6213): 1258096

Du SJ, Gong Z, Fletcher GL, Shears MA, King MJ, Idler DR, Hew CL (1992) Growth enhancement in transgenic Atlantic salmon by the use of an "all-fish" chimeric growth hormone gene construct. Nat Biotech 10:176-181

Dunham RA, Warr GW, Nichols A, Duncan PL, Argue B, Middleton D, Kucuktas H (2002) Enhanced bacterial disease resistance of transgenic channel catfish Ictalurus punctatus possessing cecropin genes. Mar Biotech 4:338-344

ECLAC, FAO, IICA (Economic Commission for Latin America and the Caribbean, Food and Agriculture Organization of the United Nations, and InterAmerican Institute for Cooperation on Agriculture) (2019) The Outlook for Agriculture and Rural Development in the Americas: A Perspective on Latin America and the Caribbean 2019-2020. San José, Costa Rica: IICA, pp 56-59. https:// repositorio.iica.int/bitstream/handle/11324/8214/ BVE19040295i.pdf;jsessionid= D941F98ED59CF544FAFFE7BA6E74D11C? sequence=2

EFSA (European Food Safety Authority) (2012) Guidance on risk assessment of food and feed from genetically modified animals and on animal health and welfare aspects. EFSA J $10: 2501$

FAO (Food and Agriculture Organization of the United Nations) (2008) Guideline for the Conduct of Food Safety Assessment of Foods derived from recombinant-DNA animals. CAC/GL 68-2008. http://www.fao.org/fileadmin/user_ upload/gmfp/resources/CXG_068e.pdf

FAO and WHO (Food and Agriculture Organization of the United Nations and World Health Organization) (2021) Codex Alimentarius: International food standards. http:// www.fao.org/fao-who-codexalimentarius/home/en/

Finardi F (2020) Food safety aspects of regulations for genetically engineered/modified (GM) animals in Brazil. https:// 752610ed-a-d8d7ceb9-s-sites.googlegroups.com/a/vt.edu/ animalbiotechresources/2020-online-workshops/FinardiGManimalsInBrazil.pdf?attachauth=ANoY7cpO9C y4piBSdDzUM-p4a9Aq9FzKHvgKWyTAnscxK_WL1k fKzaeUbcFdxcmkdTm7RAzyJnLQB9weBIXTgt9uqVFJ 
wd76y5wmdF1QoN8gW2eaIZNO78NX2_Rp92QtzTBM hxI_-a0ri5Q8y_VaShekVIrhCIyZasWqvkoLQ-XicEw7 GL0zmx Yy6CM1KeioOpbceD412YY2OdJTiSVWy0tQ_ AME4CpfpyQYV-fnJvt1Xaz29GG27QtU0wFzkmJQoD 726aJ8BHK3EI9Ca8TZLXJ_fpmHsVSrw\%3D\% $3 \mathrm{D} \&$ attredirects $=0$

Forsberg CW, Phillips JP, Golovan SP, Fan MZ, Meidinger RG, Ajakaiye A, Hilborn D, Hacker RR (2003) The Enviropig physiology, performance, and contribution to nutrient management advances in a regulated environment: the leading edge of change in the pork industry. J Anim Sci 81(Suppl_2): E68-E77

Frewer LJ (2020) Societal perspectives on gene technologies and animals in agriculture: is gene editing different? https://752610ed-a-d8d7ceb9-s-sites.googlegroups.com/a/ vt.edu/animalbiotechresources/2020-online-workshops/ FrewerSocietalPerspectives.pdf?attachauth=ANoY7cqv vIy-VCjX9zM2UL1CJQQLmOjzzJePTjO7UR4DLJUx JOgJbCrOPyzG6HteSv08SUVIybo1i2Yj6yuoKH0a 2XI28_QolxhenZoLZ0FMiyeXc1ZoIAqQv7cLz66dYzo_ mE1pb18tuYdTF9za9PCGTmOwuqNg-m0DjGrzkWB73 CXZ0PuR-RpGccJNZJG72qc5meKHxy4yTqyA4skg SvuqVyu63sfL88W-GcFvjZLHPVLWoThNsjdxmPpH DWFdNbGCvVB1gJoDvD4NBaFPGUzYsdQtyTIgLQ\% 3D $\% 3 \mathrm{D} \&$ attredirects $=0$

Frewer LJ, Fischer ARH, Brennan M, Bánáti D, Lion R, Meertens RM, Rowe G, Siegrist M, Verbeke W, Vereijken MJL (2016) Risk/benefit communication about food: a systematic review of the literature. Crit Rev Food Sci Nutr 56:1728-1745

Frewer LJ, van der Lans IA, Fischer AR, Reinders MJ, Menozzi D, Zhang X, Zimmermann KL (2013) Public perceptions of agri-food applications of genetic modification: a systematic review and meta-analysis. Tr Food Sci Technol 30:142-152

FSANZ (Food Safety Australia New Zealand) (2019) Review of food derived using new breeding techniques. https://www. foodstandards.gov.au/consumer/gmfood/Documents/ NBT\%20Final\%20report.pdf

Gallo S (2020) Growing trust in innovation: Opportunities and challenges for bringing new products to market. https:// 752610ed-a-d8d7ceb9-s-sites.googlegroups.com/a/vt.edu/ animalbiotechresources/2020-online-workshops/Gallo GrowingTrustInInnovation.pdf?attachauth=ANoY7crQk UIse0rEfcDkYjYRAiw8mBiC80Z93PFLDdJhuPeMd4H QmAn2QhhHxTK-VCYZvIygKYSwxhEB7p2Ns10CKO Bh3A7cDQTdI2MuCdoNpyPRvDKYM6nwxz03hv9dOR J3Xnab9u7LF598-ciyze4dIxmefyApi11431XW_GDdx6Y qtcwE-1Nb8LqP8oWQA-eJ0y0TDo7UqKJVamKvGNT gih9Q81V14IL4YKnqPp-cfEjGfOHSoXTb2oKKwb45yC 98IrN1dsKf2Kzw2vxlFG1XYga8vCFQ7w\%3D\%3D\& attredirects $=0$

Garcia JF (2020a) Developer/producer perspective on market readiness in South America. https://752610ed-a-d8d7ceb9s-sites.googlegroups.com/a/vt.edu/animalbiotechresources /2020-online-workshops/GarciaDeveloperPerspective MarketReadinessSA.pdf?attachauth=ANoY7coe0T3gGA TT55LjiS8TJ_X4MFu4Xt2Vv5yPW4c-PrRehzhmbEL7 QdhnfwFwTgQDuJXA7mf9S4R4C3d_SY3tmPIxZxsx2g HE3sUatz_8DxodTUy9nhP7W4jef2jhqvBd2OSBGQ4mo NwEDDrmJ8EGN77Nnexkw-ZG8GuiWM3nxvZvSIYhI
436i_Y16t6BkEljd6eP6Hh_sw5IMJEzdLgVDu2ekyqSi ZYdtjIZpC-96bwSw2NJzms7A4FawpRm-3nIKkysNhen fEJXp2e2bVUZx7VeTguBttC61Er8N5GXQjeBvYGryw $\% 3 \mathrm{D} \&$ attredirects $=0$

Garcia JF (2020b) Environmental safety aspects of regulations for genetically engineered/modified animals. https:// 752610ed-a-d8d7ceb9-s-sites.googlegroups.com/a/vt.edu/ animalbiotechresources/2020-online-workshops/ GarciaBrazil.pdf?attachauth=ANoY7cqOK9kM7f9n_ 9KX2WY-uQXZEeYJumUINg5Q8igiuWJOF9Br44JZJ Hs7xvG4rdwObUlPD7p5cQjiEp90Qb2EZeO8SNTRyM9 9kNJbd96EAw3SaD7Y82v5Rjwe24iXwMcfeJ0sP_Qpz 2IcYyc73zAZ1h1g7GD6TctPnqpv93vfEXiJlMcBP4f98yJDods2IalhKF-K0Wpy8zOn4KV6PtGFrSlo3UI 8dhlu_A0ocKW19JbA6AX1j84GJa57wJhdx6T1SUpq 8zi\&attredirects $=0$

Georges M, Charlier C, Hayes B (2019) Harnessing genomic information for livestock improvement. Nat Rev Genet 20(3):135-156

Golovan SP, Meidinger RG, Ajakaiye A, Cottrill M, Wiederkehr MZ, Barney DJ, Plante C, Pollard JW, Fan MZ, Hayes MA, Laursen J (2001) Pigs expressing salivary phytase produce low-phosphorus manure. Nat Biotechnol 19:741-745

Gordon JW, Scangos GA, Plotkin DJ, Barbosa JA, Ruddle FH (1980) Genetic transformation of mouse embryos by microinjection of purified DNA. Proc Natl Acad Sci USA 77:7380-7384

Government of Canada (2012) NSN 676: Cassie line of genetically modified Sus scrofa domestica. https://www.canada. $\mathrm{ca} /$ en/environment-climate-change/services/managingpollution/evaluating-new-substances/biotechnologyliving-organisms/risk-assessment-decisions/summary15676.html. Accessed 14 June 2021

Gratacap RL, Wargelius A, Edvardsen RB, Houston RD (2019) Potential of genome editing to improve aquaculture breeding and production. Tr Genet 35:672-684

Groenewald, H (2020) A South African perspective on the regulation of NBTs. https://752610ed-a-d8d7ceb9-s-sites. googlegroups.com/a/vt.edu/animalbiotechresources/2020online-workshops/GroenewaldRegulationNBTsSA. pdf?attachauth=ANoY7coOiZYUveG4LtMDNFukw3UR vQ18YNBLf3h6tCiV017FlOJEGLLSC3o4H2rqzbKn39 scsj4RxkDvUsIwOXog5_8ssSINQYfokTW7NRaudmuo 22SrK0pM4Gfo7mgxO-Z1rac_J1hogMW14DmLZ3Purw QxK0c2CKL4ngUpvZnxGew3rFeBhapEA91hhdTxn 25MBzTFSQ4ukap3JdLi0kpVYahn9_nhUPOamrIbxbX cnwv8_OBJ0vW74tPy2PuiSs6iFdCV82sx1TAw 5Q8fwVhapxwY_mHLYw\%3D\%3D\&attredirects $=0$

Hammer RE, Pursel VG, Rexroad CE, Wall RJ, Bolt DJ, Ebert KM, Palmiter RD, Brinster RL (1985) Production of transgenic rabbits, sheep and pigs by microinjection. Nature 315:680-683

Hansen PJ (2020) Prospects for gene introgression or gene editing as a strategy for reduction of the impact of heat stress on production and reproduction in cattle. Theriogenology 154:190-202

Hess A (2019) Argentina, Brazil and Canada outpacing U.S. in gene-editing. National Hog Farmer. https://www. nationalhogfarmer.com/agenda/argentina-brazil-andcanada-outpacing-us-gene-editing 
Hilbeck A, Andoh D eds (2004) Environmental risk assessment of genetically modified organisms, vol 1: a case study of $B t$ Cotton in Brazil. CABI International, Wallingford, UK

Hilbeck A, Andoh D, Fontes EMG eds (2006) Environmental risk assessment of genetically modified organisms, vol 2: a case study of $B t$ Maise in Kenya. CABI International, Wallingford, UK

Hillman P, Lee C, Carpenter J, Baek K, Parkhurst A (2001) Impact of hair color on thermoregulation of dairy cows to direct sunlight. In: 2001 ASAE annual meeting 1998. American Society of Agricultural and Biological Engineers, p 1. https://doi.org/10.13031/2013.23648

Holst Jensen A (2020) Proposal for revision of the Norwegian Gene Technology Act. https://752610ed-a-d8d7ceb9-ssites.googlegroups.com/a/vt.edu/animalbiotechresources/ 2020-online-workshops/HolstJensenGeneEditingAnimals Workshop.pdf?attachauth=ANoY7coPFN7A1NVYSS0z9 nBsxx6Usa3h6tQlreY6kLdXlz0E-AMfG29HkO8yGk8 fiGeMGbQqRFPM1yj48rLqz8EBXKkOUnZwHfoFKdsq eZsxVRafwu9CGoUuvy02s4mOQ4WW-Fxn4WEJhOP Axj8Um9KXsDtzZB9aZWhxttHn-w-LmceoweiiKbSuc VK-Cup57tfRnA6M0virxfQNQ0QtiQXb1_a0K_nLtbio XFTZ3q2nq_nDYExmpX1VzBFzgOEbj3LO9_DlzD19yo X8Ce6fEFyL54ri19VKuA\%3D\%3D\&attredirects $=0$

Jenko J, Gorjanc G, Cleveland MA, Varshney RK, Whitelaw CB, Woolliams JA, Hickey JM (2015) Potential of promotion of alleles by genome editing to improve quantitative traits in livestock breeding programs. Genet Selec Evol 47(1): $1-4$

Kanelakis KC (2020) Food safety considerations for animals with intentional genomic alterations. https://752610ed-ad8d7ceb9-s-sites.googlegroups.com/a/vt.edu/animalbio techresources/2020-online-workshops/Kanelakis-Food SafetyConsiderationsForAnimalsWithIGAs.pdf?attacha uth=ANoY7crS5ddr6nA2wOGc3_F6ozhTnHOG_Emf VelOw614lbLRDPIIs7qaewV280wy3p7cX52CcENDE 8_V7RKEZKSOzoZ-ye764GPKu0FJeJsbcfz8fTLQ2Epf aPxC4idfRCbwDy_ZA3DZhmSBdv3XsPvBee15-A61FyB-cM3g-I1tZ-HnEKhvo0j8Vy5a0jVUqxDlpb_2_cGV BWiqK51ZacPzxhjYNj5sW8HeUGWso3aqG6TXOwVEgh85SMr1AMGTcX-vfEErHgLKOrc8wpLhsZMmljvLI0W6a0yMXpa_KFoPSFfTebM\%3D\&attredirects $=0$

Kapuscinski AR, Hayes KR, Li S, Dana G, Hallerman EM, Schei PJ (eds) (2007) Environmental risk assessment of genetically modified organisms, vol 3: methodologies for transgenic fish. CABI International, Wallingford, UK

Kelly L (2020) Regulatory frameworks and updates for food safety assessment for genetically engineered/modified animals: report from Australia. https://752610ed-ad8d7ceb9-s-sites.googlegroups.com/a/vt.edu/ animalbiotechresources/2020-online-workshops/Kelly_ Australia.pdf?attachauth=ANoY7cqrQCVnkHDddfP6TQ4VfewF4xDpHGKfhvRjKgCm2scranHS-bgW9jain44gsBUxk574vGijOIhy9rAjxP-nalSY8zhsKAPYKh 7RXPkUxg3fW1OBk22UpOiGlBb9fEc9ph4UTWTxs4z sp1VF337ur-uQE48Stcp8glF1n3b9RCtffUHQKA9kYn Zq6Fafm-Nkyl0UE8SiSriqkXKwvPC3zFQGU3pSNRjW UVf1YJzvN1_y_IhWfhGBtA1re4e02vbtv286VH \&attredirects $=0$

Kemp S (2020) ILRI contained use for research. https:// 752610ed-a-d8d7ceb9-s-sites.googlegroups.com/a/vt.edu/
animalbiotechresources/2020-online-workshops/Kemp RegulatoryApproaches.pdf?attachauth=ANoY7cqc1fiNN PVzH-iXPe26xiltyy_-ZN6hbIegxYrbUz1FQW4FIJ23p VyL7wKxmDxc8frGzWZn9JZAhLeuVN_Mudmjfkg4y TRzz3ujhO0rvOYmQoYxMYb-x_A5QzQwrTouUuWK k1_4jRjKjfpbhVlW-oYNMwl_h0sR-sttxgwQp9hGHrFZ oFZ2YwHzEPQq85RqsDjr6HelbiVdYBYLxUT7VT8u RLKpCCQDb2A3n32pfDDxDySXwXWfWv8fzxXww zVlHYsLSNU4KkL_0vED5xkZvrshH5-Mbg\%3D\% 3D\&attredirects $=0$

Kim J, Cho JY, Kim J-W, Kim H-C, Noh JK, Kim Y-O, Hwang H-K, Kim W-J, Yeo S-Y, An CM, Park JY, Kong HJ (2019) CRISPR/Cas9-mediated myostatin disruption enhances muscle mass in the olive flounder Paralichthys olivaceus. Aquaculture 512:734336

King VL, Denise SK, Armstrong DV, Torabi M, Wiersma F (1988) Effects of a hot climate on the performance of first lactation Holstein cows grouped by coat color. J Dairy Sci 71:1093-1096

Kishimoto K, Washio Y, Yoshiura Y, Toyoda A, Ueno T, Fukuyama H, Kato K, Kinoshita M (2018) Production of a breed of red sea bream Pagrus major with an increase of skeletal muscle mass and reduced body length by genome editing with CRISPR/Cas9. Aquaculture 495:415-427

Kling J (2009) First US approval for a transgenic animal drug. Nat Biotechnol 27:302-304

Knapton S (2017) Genetically engineered superhorses to be born in 2019 could soon compete in the Olympics. The Telegraph, 26 December 2017. https://www.telegraph.co.uk/ science/2017/12/26/genetically-engineered-super-horsesborn-2019-could-soon-compete/.

Laible G, Cole S-A, Brophy B, Wei J, Leath S, Jivanji S, Littlejohn MD, Wells DN (2020) Holstein Friesian dairy cattle edited for diluted coat color as adaptation to climate change. bioRxiv 2020.09.15.298950

Ledford H (2019) Creators of gene-edited animals bypass U.S. market. Nature 566:433-434

Lee HJ, Lee KY, Jung KM, Park KJ, Lee KO, Suh JY, Yao Y, Nair V, Han JY (2017) Precise gene editing of chicken $\mathrm{Na}^{+} / \mathrm{H}^{+}$exchange type 1 (chNHE1) confers resistance to avian leukosis virus subgroup J (ALV-J). Devel Comp Immunol 77:340-349

Liu XF, Wei ZY, Bai CL, Ding XB, Li X, Su GH, Cheng L, Zhang L, Guo H, Li GP (2017) Insights into the function of n-3 PUFAs in fat-1 transgenic cattle. J Lipid Res 58:1524-1535

Lyall J, Irvine RM, Sherman A, McKinley TJ, Núñez A, Purdie A, Outtrim L, Brown IH, Rolleston-Smith G, Sang H, Tiley L (2011) Suppression of avian influenza transmission in genetically modified chickens. Science 331:223-226

Maga EA, Cullor JS, Smith W, Anderson GB, Murray JD (2006) Human lysozyme expressed in the mammary gland of transgenic dairy goats can inhibit the growth of bacteria that cause mastitis and the cold-spoilage of milk. Foodbourne Patho Dis 3:384-392

Maggi A (2020) Food safety aspects of regulations for genetically engineered/modified (GM) animals in Argentina. https://752610ed-a-d8d7ceb9-s-sites.googlegroups.com/a/ vt.edu/animalbiotechresources/2020-online-workshops/ Maggi-GMAfoodFeedArgentina.pdf?attachauth= ANoY7cpe1DI932bKFKAHJt5v2bhkn5Ffivg-sNv_ 
Vyas2Sx-534ekUfuFNXRheJWO08WaVL5Lccx2Oao z3W1_oTML5Qsb_Z03Nn00N-oyq1_LO3jyiphp04cj6 hzdaBbXwV4jjMw4ZBzk819pvjSnwi28laAAN3BxjLL t4rVdj2845ZE7QqZPJoUJG-VgVrvSG42NI0X_yWd85 ysbzawAV69bGrBkAGd27dbieq4niWc9Uh9RTu4o6Fw qMIHt30ztVZeKcq4zlVoK_eef2yhNkz_4bi1uCpsw\% $3 \mathrm{D} \% 3 \mathrm{D} \&$ attredirects $=0$

Majumdar SS, Jain NK (2020) Environmental safety aspects of regulations for genetically engineered/modified animals (confined use/environmental release). https://752610ed-ad8d7ceb9-s-sites.googlegroups.com/a/vt.edu/animal biotechresources/2020-online-workshops/SessionIIIAge nda100720.pdf?attachauth=ANoY7cq0PZPG12hxjDfvg 3u-z-qkwpxZzrvb13IMskpSkEuoUbpJ4ay6Nf41FaG1 5Rw5SUO5qpP2q6J4CfnObU7Nlwb9x9gqjHZ4Yhu 6pbKKo_-Do9tv3bM4ROHhKCpVqSJAPb_3efmWKzA x0WJv-hJmYy9E4vNdJmn1CStfM2Wg5-izvXD5zC sLOjFSiJz1FsVk9Nz_6oZ7w5eOdOzXN11 6gSiFJFxBDuu-LCh7W3SWyxyJZ0AsENv5BPuyjzSLd_ 816RYhD4mmeP2C_ld7LHclAvG8ohB4qg\%3D\% $3 \mathrm{D} \&$ attredirects $=0$

Meuwissen THE (2007) Genomic selection: marker-assisted selection on a genome-wide scale. J Anim Breed Genet 124:321-322

MHLW (Ministry of Health, Labor and Welfare, Japan) (2021) List of foods and additives notified based on the food hygiene handling guidelines for foods and additives that apply genome editing technology. https://www.mhlw.go. jp/stf/seisakunitsuite/bunya/kenkou_iryou/shokuhin/bio/ genomed/newpage_00010.html (in Japanese). Accessed 8 Nov 2021

Mingala CN (2020) Food safety aspects of regulations for genetically engineered/modified (GM) animals. https:// 752610ed-a-d8d7ceb9-s-sites.googlegroups.com/a/vt.edu/ animalbiotechresources/2020-online-workshops/MingalaFoodSafetyOnGManimals.pdf?attachauth=ANoY7co3 FdcQjczQTwdpAQzCovAp7jRF-_vnUdlF2w1JbrdpsI Man3yDhPKc9qa-f92bFyUb_P5clCDz4VshDBrW2t VGVGyhzYAT3tpcTaCypA8SniMefvG7NJAZGThaAy7 EICoSFyN7xr6rAIeuhIOzYm98EavrbD-1XLvqNedR 5jN-doaTaTv6rJiPkmq153zekJXtEua95E5-bBgWXyO hfGKp0GR0Rb71t81z5zdl7kEzwO2Hl6-hzGCB6eRN MN2ibB9CDcY63u_-QvDgYrPZ35AgFX8nA\%3D\% 3 D\&attredirects $=0$

Moore T (2020) Consumer perceptions of animal biotechnology in agriculture. https://752610ed-a-d8d7ceb9-s-sites. googlegroups.com/a/vt.edu/animalbiotechresources/2020online-workshops/MooreConsumerPerceptionsof AnimalBiotech.pdf?attachauth=ANoY7coDzdCU8gXfY41BskIWEoTFXdftfATBgZHdM07x_n8L1rjdUkNtH K8sq8FzY0SBsMEApxW7Y9zbMBvF8O3ni6NVTPfhgnrRKDEDLa2fdHndtoHEDAmMIdk36C-uRUnUX0 g3Le7mTEC8xnty38opy_xTIo_IYbLowPxbkdqMKfJsL 5P1104WyGX3YPpc7MQJn1lwYdnsM0a1tXbLe5RzIY xJxqeTxSDxWeaKbESzLsGqIj8KICPfYHVG6sdzig PpWDDOEviZHdSq-BcM785Fe1ao_6vEt8SqD1q2-_ U1Qlmib1178\%3D\&attredirects $=0$

Nascimento R (2020) Current status of the regulatory approaches for genome edited (GnEd) animals: Brazilian experience. https://752610ed-a-d8d7ceb9-s-sites.googlegroups. com/a/vt.edu/animalbiotechresources/2020-online-
workshops/NacimentoAnimalBiothecBrazilCTNBio. pdf?attachauth=ANoY7crgjeL7shmdJWcIfybHRoK9R6 7_iV_pEm9hoWY98sSSLIo1WyOkFueiFNINK_uOgTk JNYCBnNx9gk3LCOVhpJ_R2rskVpQkdapX9uSKXnPO pK4PTEl_2ezzMnEB4_NaWrNRNgwAci1CtIJoKjxsp_ 46spbkLEY1Ws5d-annf9miLwcWZJ4Nq4f5Oo1vNr Mr9qzvhfmYw9uBPb3Q5ah5xf_w0aAVddQdeBYQfXRJ q7G_XjoPxNehrB5HWF4aeNsJh33sBplinLJhDY8ZE QBoH-rjLOJA8w\%3D\%3D\&attredirects $=0$

Navarro-Serna S, Vilarino M, Park I, Gadea J, Ross PJ (2020) Livestock gene editing by one-step embryo manipulation. J Equine Vet Sci 89:103025

Nengomasha E (2020) African Union policies, strategies and guidance documents that identify science, technology and innovation as an important vehicle for socio-economic development. https://752610ed-a-d8d7ceb9-s-sites.google groups.com/a/vt.edu/animalbiotechresources/2020-onlineworkshops/Nengomasha-AU-IBARPresentation.pdf?att achauth=ANoY7co2Laqm-1tzr3-AoY8KhamDBsA0Xah nFklB-guUUh2VF93c4vlhvWWzlfn1_Ft7jM20abDZm 2rUY0AwDpmdiG-2Zyk3GwviU0e2vmTltjPEXXobAEwRGh5WXG_VHjGNq1-4iJC5dUEa2_2Xfzxsem_ TIipjGVAj2KqCY61h65uCZ_kazlVZGcu5gE_Rwixt wjdAjPAJxb1plsfN5jhEIuJREhfrIyO3GHLCy4CbaZYV XQnpQ01RhApq2yeERdGOLyrI6yGi7x6bDB5n312j Gj6k6uaA\%3D\%3D\&attredirects $=0$

Nesbitt C (2020) The state of innovation: Opportunities and challenges bringing animal biotech products to market. https://752610ed-a-d8d7ceb9-s-sites.googlegroups.com/a/ vt.edu/animalbiotechresources/2020-online-workshops/ NesbittAnimalBiotechRegn.pdf?attachauth=ANoY7cpl 02693SN4ottwtSh8NSEOqYLnC6Do7Fz7C0Tvz43 F0QU3wabBmlXsZy2qaFibqjwRLYJshdjBZ8UkKtnn_ KiuZ7icAUavjFkbYHeoWI1ZTVNkfpISk8hsnKBWO igGE4QdeMkqjqesDAtQmFacNhR90gIsNWnG-S6TqrK zSDBHXKnfltA5n2ImBDTcvdCiGEqIgqwCxrYW9XE6 kfUoX4-ZkjdfLKWAWTOCvR462yoF-aY4XbXFmww JrMxJLRu21ZFI_5IpYdm7Et8AiaibK8DX42xxg\%3D\% 3D\&attredirects $=0$

NRC (National Research Council) (1996) Understanding Risk: Informing Decisions in a Democratic Society. National Academy Press, Washington, DC. www.nap.edu

NRC (National Research Council) (2002) Animal biotechnology: science-based concerns. National Academy Press, Washington, DC. www.nap.edu

Neumann EJ, Kliebenstein JB, Johnson CD, Mabry JW, Bush EJ, Seitzinger AH, Green AL, Zimmerman JJ (2005) Assessment of the economic impact of porcine reproductive and respiratory syndrome on swine production in the United States. J Am Vet Med Assoc 227(3):385-392

Ogoyi D (2020) Environmental safety aspects of regulations for GM animals in Kenya. https://752610ed-a-d8d7ceb9-ssites.googlegroups.com/a/vt.edu/animalbiotechresources/ 2020-online-workshops/SessionIIAgenda100520.pdf? attachauth=ANoY7cpciChYQP-ELb6z9f7TiT8TOfAUG E02Y2QVKFNaPnP3BX88-nPsxyLr1LVWayjgj2OhEss U_jcaKM2ZuMnAK7EMG3Z-ShO6X5HqfJvjzZDyRlm LuSI5BZbOOHW4-RHrcjUvjA-SNLOZRudtJcbScrTxa DWSXAUs6bBx1ZmuKk0b3ICOU_RgEyqI80LAA_ ZIhMM0IacVSGmhbWS2olOx_0oNwuDXVcBNltMt3m 
VXALGN3A6AlPeDrxIrNjL81Fs7qf4k_foM\&attredirec ts $=0$

Oishi I, Yoshii K, Miyahara D, Kagami H, Tagami T (2016) Targeted mutagenesis in chicken using CRISPR/Cas9 system. Sci Rep 6:23980

Omeje SI, Gidado RS (2020) The state of animal biotechnology practices and biosafety regulation in Nigeria. https:// 752610ed-a-d8d7ceb9-s-sites.googlegroups.com/a/vt.edu/ animalbiotechresources/2020-online-workshops/Omeje AndGidadoNigeria.pdf?attachauth $=$ ANoY7cpJ46HrDhR n0tKqhEVkLqw65Y1VrEZjAHwdOrA7x3JF448Q1QN7 OYg3z5oF3qqlKUeOhvMOAuAjogfiiS9qK4yl7r1A0f wn9xLrJg1jiIzHVKpIPwpfGADPil0i1fl3W-uP_kMP IIbFsX6FQfQWtqf84pEq_IPY_07-Z86w7viCjoZWkX S9rzquODTRR_RzXj3fAV4UXQ-GpRFbYHu51zhYoy a5SgLMTohkMRWvrW0nZODSTiVadsPEPMIYeCt sdzu-6fM5\&attredirects $=0$

Owen JR, Hennig SL, McNabb BR, Lin JC, Young AE, Murray JD, Ross PJ, Van Eenennaam AL (2020) Harnessing endogenous repair mechanisms for targeted gene knock-in of bovine embryos. Sci Rep 10(1):16031. https://doi.org/ 10.1038/s41598-020-72902-X

Palmiter RD, Brinster RL, Hammer RE, Trumbauer ME, Rosenfeld MG, Birnberg NC, Evans RM (1982) Dramatic growth of mice that develop from eggs microinjected with metallothionein-growth hormone fusion genes. Nature 300:611-615

Palmiter RD, Norstedt G, Gelinas RE, Hammer RE, Brinster RL (1983) Metallothionein-human GH fusion genes stimulate growth of mice. Science 222:809-814

Park KE, Frey JF, Waters J, Simpson SG, Coutu C, Plummer S, Campbell M, Donovan DM, Telugu BP (2020) One-step homology mediated CRISPR-Cas editing in zygotes for generating genome edited cattle. CRISPR J 3(6):523-534

Pew Research Center (2018) Most Americans accept genetic engineering of animals that benefits human health, but many oppose other uses: Public concerns about animal biotechnology focus on risks to animals, humans and the ecosystem. https://www.pewresearch.org/science/2018/ 08/16/most-americans-accept-genetic-engineering-ofanimals-that-benefits-human-health-but-many-opposeother-uses/. Accessed 31 Oct 2021

Pickar-Oliver A, Gersbach CA (2019) The next generation of CRISPR-Cas technologies and applications. Nat Rev Mol Cell Biol 20(8):490-507. https://doi.org/10.1038/s41580019-0131-5

Porto-Neto LR, Bickhart DM, Landaeta-Hernandez AJ, Utsunomiya YT, Pagan M, Jimenez E, Hansen PJ, Dikmen S, Schroeder SG, Kim ES, Sun J, Crespo E, Amati N, Cole JB, Null DJ, Garcia JF, Reverter A, Barendse W, Sonstegard TS (2018) Convergent evolution of slick coat in cattle through truncation mutations in the prolactin receptor. Front Genet 9:57

Pursel VG, Bolt DJ, Miller KF, Pinkert CA, Hammer RE, Palmiter RD, Brinster RL (1990) Expression and performance in transgenic pigs. J Repro Fertil 40:235-245

Rhodes J, Groenewald H (2020) Risk analysis for contained use R\&D activities with GM aquatic organisms. https:// 752610ed-a-d8d7ceb9-s-sites.googlegroups.com/a/vt.edu/ animalbiotechresources/2020-online-workshops/Rhodes AndGroenewaldSouthAfrica.pdf?attachauth=ANoY7co_
Sy7oniPBgd6pEmVMlXW7XuOLz9QjkZCCToz4hWJ O254U41yH15sPVojY2I_b44yd07iQvyeqeVDJ3I3x8PX tok16B3N7Ie13mSLV7VdQpoqD4TSusokeWQmtrcIIpk_RGzXKwLpmtyohWWUBh6HcnaoT-ErF1lxf0H 4YMGsiDRbZUbI6qxFnhNCYGKKUPgH4CNrbh_3tL h1yeiF87ZOL0VXCQdtvq0e3nzyeGbV99LX7S4JZTqq Ykgc6SODrFhDXjf3Aw7A2hR6SMVGRXtGaAOHjA\% 3D $\% 3 \mathrm{D} \&$ attredirects $=0$

Richt JA, Kasinathan P, Hamir AN, Castilla J, Sathiyaseelan T, Vargas F, Sathiyaseelan J, Wu H, Matsushita H, Koster J, Kato S (2007) Production of cattle lacking prion protein. Nature Biotechnol 25:132-138

Roca, MM, Parrot W, Andrade PP (2015) Genetically modified organisms-environmental risk assessment guide. International Life Sciences Institute of Brasil, São Paulo, Brazil. http://2015.igem.org/wiki/images/9/98/Tec_Guadalajara_ ERA_Guide.pdf, 89 pp

Salces AJ (2020) Current status of environmental regulation on GM animals. https://752610ed-a-d8d7ceb9-s-sites. googlegroups.com/a/vt.edu/animalbiotechresources/2020online-workshops/Salces\%20-\%20Philippines. pdf?attachauth=ANoY7coggd1bv5RDScVIg_wF_qq15trIxBtuIswFH4mmxKyBqEi1dT9mL3o2JMcUo8r6YQwejK6v8P0fk0hdczf9ujdypLSxEUFplJ9BjLh_iKJFmfwq HDkcYtFWJ7C1_ePZ_3rIU22QSvGsc_BtLWei_aiGIp YoOcg9J7WtHHGuabaU9M9otRPaBAD3YedN2yG_ qNow9bhgCogOmo-tZN-FuDiYTudmRo0laX_1zAq6y cJ4wVIpcOh84Bo0oADJCLnHtEPZgO\&attredirects $=0$

Sammartino, D (2020) Cattle. https://752610ed-a-d8d7ceb9-ssites.googlegroups.com/a/vt.edu/animalbiotechresources/ 2020-online-workshops/SammartinoCattle.pdf? attachauth=ANoY7cps3h96CW8g3F8bY2GKX8PIfY TFA-xsWyGxIg9qxzlIsjB88FNdWS0vOQEiSkzbE6mw SNxedtlsdt-0acw-JR7BAHr0MZMTrBximSEUeTOE0Pw yiMwuYefA1dDkyhAHQc6pPO6evff1CeVu_Jw6ZZ dDRq8zH-HFtvdBrDxpCVUayiAeAcWTdYAVJBa3ZIzfjfQQxgvKwYj93SyoMuc0vcHgUEtdfFNqz 9t4bxuBIq84bvw9jdjyn1_58VWflVNIcKIFcb5\&attre directs $=0 \&$ revision $=1$

Schoonjans R, Devos Y, Waigmann E (2020) EFSA guidance on ERA for GM animals. https://752610ed-a-d8d7ceb9-ssites.googlegroups.com/a/vt.edu/animalbiotechresources/ 2020-online-workshops/SchoonjansEFSA_ERA_GM_ Animals.pdf?attachauth=ANoY7coMjOdkP6j9 1MIF3zHM3fyrKf02EfOdlsMDW7Xjrh_2P9Bo3P8onVjjsmQZJIO4qzoEBfp049Ms0jtmUJA3nzAk510jO22aPK_HsD1NqWWzX9LS1O6DBLhtPfR5 DzkxjuhOCJ_6jm-aBtpvxZsnB8UITjIbEjljQbRjolgy_ qrSyHaMbcpyxzNtAc-twfk-ZrXseSF2TWIY2bJqe3 D2j9v4PUshm2tSDB8UTC9tBSIVWwPphgGDn0pQh1noNrjDyE6FpqtBbckBtLc8slVNyCvtcw\%3D\% 3D\&attredirects $=0$

Secretariat of the Convention on Biological Diversity (2000) Cartagena protocol on biosafety to the convention on biological diversity: text and annexes. Secretariat of the Convention on Biological Diversity, Montreal

Shirley M (2015) Sebelipase alfa: first global approval. Drugs 75:1935-1940

Sonstegard TS (2020) Precision crossbreeding for smallholder dairies: an investment in our future. https://752610ed-ad8d7ceb9-s-sites.googlegroups.com/a/vt.edu/ 
animalbiotechresources/2020-online-workshops/Sonste gardPrecisionCrossbreeding.pdf?attachauth=ANoY7cp 7jfI8LZWFA-BPTk83mPzE3ECK58yxG0AjEDLi5I6g QpeA2Bmzjcv6BfEZbNGoWEtJBFP5yBHPoVGLHk_sXc2n3OZ9ZcAXRLo6ygxs923-xHtKxxJqmbYaE4_F2R eJa-EdPUwUHgvlu8AKoy_C_3HOLUJQJ4EOidm09A 1B-T3eqTbkpdlAtDAxVaNOmD2HHPBkIzRD7Mp4 FCR9qGJ1-9QZu8nBCe5QVk_x9Fp6OEA38gWrdVjj aS1U-3xJb8TI6mrPzCMpDHPjW7nkj1hubFFeS-TsQ\% $3 \mathrm{D} \% 3 \mathrm{D} \&$ attredirects $=0$

Strabala T (2020) The regulation of animal biotechnology in New Zealand. https://752610ed-a-d8d7ceb9-s-sites. googlegroups.com/a/vt.edu/animalbiotechresources/2020online-workshops/StrabalaRegulationOfAnimal BiotechInNZ.pdf?attachauth=ANoY7cqzECUH0wLb7a bVfYpzW23ruY230PWIETDp-WsFWpjNOTDH4uY QOHt5vkQSyOVLQESKEj0ZiW3tOegoX89WnGVK Hc7veV3I3wHzw4HnVOAeVOZIB1O3uYRJefDOoIx 0M1tLEj0x99X52Db7gltqX1TjVIVg9C3b7H-ntSR wiKt0bNbytmtGE9WbeDbm9Q5eVbheoxegG7Jj9DYTx2BvTowEyx73sFi-RR2Zg6m0TwxJRz-zLw5E0Rm 8Ff6De1ZAQBfVry_XtNR3E0rkRvZNhUa_wAEoA\% 3D $\% 3 \mathrm{D} \&$ attredirects $=0$

Stokstad E (2021) Thaw coming for U.K. gene-editing regulations. Science 372(6545):895

Synthetic Biology Future Science Platform (2020) Public perceptions of using synthetic biology to prevent the culling of male chicks. CSIRO, Australia. https://research.csiro.au/ synthetic-biology-fsp/wp-content/uploads/sites/140/2020/ 12/20-00137_LW_SynBioSurveyResults_Chicks_WEB_ 201113.pdf

Tait-Burkard C, Doeschl-Wilson A, McGrew MJ, Archibald AL, Sang HM, Houston RD, Whitelaw CB, Watson M (2018) Livestock 2.0-genome editing for fitter, healthier, and more productive farmed animals. Genome Biol 19:204. https://doi.org/10.1186/s13059-018-1583-1

Tan W, Carlson DF, Lancto CA, Garbe JR, Webster DA, Hackett PB, Fahrenkrug SC (2013) Efficient, non-meiotic introgression in livestock using custom endonucleases. Proc Natl Acad Sci USA 110:16526-16531.

Telugu B (2020) Rational selection of traits using site-specific nucleases. https://752610ed-a-d8d7ceb9-s-sites.google groups.com/a/vt.edu/animalbiotechresources/2020-onlineworkshops/TeluguSwine.pdf?attachauth=ANoY7coh88xy 5jj4foIwmqiQi-EMBAYuzLAO7rz7OB_20ER63edhn4u 2pM-GSqilUUNyvffS-Sh15vN2DEgwcQzVpphFCev BeC5BRrToZXePyaFp9d2_WdiGi8155oimiSQMIMgece66iIsgo4TDVgUdgqO7RSppk6cjNT2mLk72Do3c ZTbjX2xoZhkc6HeeMG3XKw29kp7btTVtu7jp5XNg96Zrozw3SkNw9T7CKcA2uA09PmHgi2lZNH0tQmuXVwrn2AcGN\&attredirects $=0 \&$ revision $=1$

Tong J, Wei H, Liu X, Hu W, Bi M, Wang Y, Li Q, Li N (2011) Production of recombinant human lysozyme in the milk of transgenic pigs. Trans Res 20:417-419

Tsuda M, Ohsawa R (2020) Regulatory status of genome-edited organisms under the Japanese Cartagena Act. https:// 752610ed-a-d8d7ceb9-s-sites.googlegroups.com/a/vt.edu/ animalbiotechresources/2020-online-workshops/Tsuda GenomeEditingJapan.pdf?attachauth=ANoY7cqEJ6poQAYwllsrrYTKbm7j4BKD9JdldD0EUY6YGPzVOQ wBGaBs-7_KaM6jBSolGc438D3zd1LvX6IAkLX_5QJf
cB7dMM3s2ZcS7PGeVxdPyr4qcwxweL10o59o44Nv TFChjAtFJsNVJ8eNEOMq1ggLJ-td3lq0pwImAWHB PjlW8RC2JkzpZwgFvOTNtlpYNmYzZNR5ib4QkKL1_ Ls0ov7pQ1ClUsJMDk0qn1dGN9azmRNDiis8tsRB YeK9SknKchH34lcuiOfNXj8HdilyBPs-X717A\%3D\% 3D\&attredirects $=0$

Tsuda M, Watanabe KN, Ohsawa R (2019) Regulatory status of genome-edited organisms under the Japanese Cartagena Act. Front Bioeng Biotechnol 7:387

U.S. Departrment of Agriculture-Animal and Plant Health Inspection Service (2020) Regulation of the movement of animals modified or developed by genetic engineering. Fed Regist 85(248):84269-84275

U.S. Food and Drug Administration (1993) Posilac for increasing production of marketable milk in lactating dairy cows. https://animaldrugsatfda.fda.gov/adafda/app/search/ public/document/downloadFoi/512. Accessed 14 June 2021

U.S. Food and Drug Administration (2009) FDA approves orphan drug ATryn to treat rare clotting disorder. http:// wayback.archive-it.org/7993/20170111175119/http:// www.fda.gov/NewsEvents/Newsroom/

PressAnnouncements/ucm109074.htm. Accessed 14 June 2021

U.S. Food and Drug Administration (2018) FDA approves application for AquaBounty salmon facility in Indiana. https://www.fda.gov/animal-veterinary/cvm-updates/fdaapproves-application-aquabounty-salmon-facility-indiana. Accessed 8 February 2021

U.S. Food and Drug Administration (2020) FDA approves firstof-its-kind intentional genomic alteration in line of domestic pig for both human food, potential therapeutic uses. FDA News Release, 14 December 2020. https:// www.fda.gov/news-events/press-announcements/fdaapproves-first-its-kind-intentional-genomic-alterationline-domestic-pigs-both-human-food

U.S. Food and Drug Adminstration (2021). Bovine somatotropin (bST). https://www.fda.gov/animal-veterinary/ product-safety-information/bovine-somatotropin-bst. Accessed 14 June 2021

Van Eenennaam AL, Silva FD, Trott JF, Zilberman D (2021) Genetic engineering of livestock: the opportunity cost of regulatory delay. Annu Rev Anim Biosci 9:453-478

Van Eenennaam AL, Wells KD, Murray JD (2019) Proposed US regulation of gene-edited food animals is not fit for purpose. NPJ Sci Food 3:1-7

van Veen HA, Koiter J, Vogelezang CJ, van Wessel N, van Dam T, Velterop I, van Houdt K, Kupers L, Horbach D, Salaheddine M, Nuijens JH, Mannesse MLM (2012) Characterization of recombinant human $\mathrm{C} 1$ inhibitor secreted in milk of transgenic rabbits. J Biotechnol 162:319-326

Walton M (2020) A developer's perception of market readiness. https://752610ed-a-d8d7ceb9-s-sites.googlegroups.com/a/ vt.edu/animalbiotechresources/2020-online-workshops/ WaltonProducerPerspectiveMarketReadiness.pdf?attach auth=ANoY7cqDnt_P0bkuJ_v1L57J9AsaDWnkbCXM0 g5_dOCz8Iq576csrJ-zl6cuf9U-hiEreDpIxi1rY4DLNrdrn CmJdjboErIvd7L22LjRPHLsQFzHtDkZIys-nzJ1NBbpkx 540TpQHfhBb6g3hVaVX51Fwwd_su2dToPmHpAtdhH_ZfVBMMSvkCddm8ygGvh0paFaVRyUt5NbxyTV19b vkQAae3tJAQ52aWFe2vjbM6q3hk3MUjpXfX7iCSoZw 
ETf3cr9-hrQMqx97cHD-0Ik3QT4o0IJUMW0Rwf0bAo qtYGjs1HUP3gso \%3D\&attredirects $=0$

Wargelius A, Leininger S, Skaftnesmo KO, Kleppe L, Andersson E, Taranger GL, Schulz RW, Edvardsen RB (2016) Dnd knockout ablates germ cells and demonstrates germ cell independent sex differentiation in Atlantic salmon. Sci Rep 6:1-8

Whelan A, Gutti P, Lema MA (2020) Gene editing regulation and innovation economics. Front Bioeng Biotechnol 8:303

Whelan A (2020) Regulatory approaches. https://752610ed-ad8d7ceb9-s-sites.googlegroups.com/a/vt.edu/animal biotechresources/2020-online-workshops/WhelanGeno meEditingArgentina.pdf?attachauth=ANoY7cpugd_FiAe DKSyMoP20rqmj2vLQd8HhaC_49i_TrpnM26NIh9Vbw 1mICd13W7n_0_Nv8rbGKcQhNhB4t2_g1-zzEJTU6RCAIiiOCDzAokOVals5hKffXDn0Jo10M7d8yIeL4Gw 8DdJEzD4eu4yrWdx1q2Tya1kKuNRrhJuVDtq13LEOQ cV_TYGbRy0Qf4JuWXboy5fbCXeNxp0S7hY0rRqrer4r EWSEAi4cn79ZgLn6pF34ADh8j-6iuWC9pORd-nY8o 0Dk0cKT2O4qgWDzRfkUgLyrg\%3D\%3D\&attredirects $=0$

Whitworth KM, Lee K, Benne JA, Beaton BP, Spate LD, Murphy SL, Samuel MS, Mao J, O'Gorman C, Walters EM, Murphy CN, Driver J, Mileham A, McLaren D, Wells KD, Prather RS (2014) Use of the CRISPR/Cas9 system to produce genetically engineered pigs from in vitro-derived oocytes and embryos. Biol Reprod 91:78. https://doi.org/ 10.1095/biolreprod.114.121723

Whitworth KM, Prather RS (2017) Gene editing as applied to prevention of reproductive porcine reproductive and respiratory syndrome. Molec Repro Devel 84(9):926-933
Wei J, Wagner S, Maclean P, Brophy B, Cole S, Smolenski G, Carlson DF, Fahrenkrug SC, Wells DN, Laible G (2018) Cattle with a precise, zygote-mediated deletion safely eliminate the major milk allergen beta-lactoglobulin. Sci Rep 8(1):1-3

Wu WY, Lebbink JHG, Kanaar R, Geijsen N, van der Oost J (2018) Genome editing by natural and engineered CRISPR-associated nucleases. Nat Chem Biol 14:642-651

Xu K, Zhou Y, Mu Y, Liu Z, Hou S, Xiong Y, Fang L, Ge C, Wei Y, Zhang X, Xu C. (2020). CD163 and pAPN double-geneknockout pigs are resistant to three viruses while maintaining normal production performance. eLIFE, 9:e57132

Yomiuri Shimbun (2021) Kyoto firm puts genome-edited tiger puffer on the table. The Japan News, 1 November, 2021. https://the-japan-news.com/news/article/0007936055. Accessed 3 November 2021

Zhang X, Wang F, Dong Z, Dong X, Chi J, Chen H, Zhao Q, Li $\mathrm{K}$ (2020) A new strain of yellow catfish carrying genome edited myostatin alleles exhibits double muscling phenotype with hyperplasia. Aquaculture 523:735187

Zhong Z, Niu P, Wang M, Huang G, Xu S, Sun Y, Xu X, Hou Y, Sun X, Yan Y, Wang H (2016) Targeted disruption of $s p 7$ and myostatin with CRISPR-Cas9 results in severe bone defects and more muscular cells in common carp. Sci Rep 6:22953

Zhu B, Ge W (2018) Genome editing in fishes and their applications. Gen Comp Endocrinol 257:3-12

Publisher's Note Springer Nature remains neutral with regard to jurisdictional claims in published maps and institutional affiliations. 